\title{
Holosteans contextualize the role of the teleost genome duplication in promoting the rise of evolutionary novelties in the ray-finned fish innate immune system
}

\author{
Alex Dornburg ${ }^{\mathrm{a}, *}$, Dustin J. Wcisel ${ }^{\mathrm{b}}$, Katerina Zapfe ${ }^{\mathrm{a}}$, Emma Ferraro ${ }^{\mathrm{c}}$, \\ Lindsay Roupe-Abrams ${ }^{c}$, Andrew W. Thompson ${ }^{d}$, Ingo Braasch ${ }^{d}$, Tatsuya Ota ${ }^{e}$ and \\ Jeffrey A. Yoder ${ }^{b, f, g, t}$
}

a. Department of Bioinformatics and Genomics, University of North Carolina at Charlotte, Charlotte, NC USA

b. Department of Molecular Biomedical Sciences, North Carolina State University, Raleigh, NC, USA

c. North Carolina Museum of Natural Sciences, Raleigh, NC, USA

d. Department of Integrative Biology and Ecology, Evolution, and Behavior Program, Michigan State University, East Lansing, MI, USA

e. Department of Evolutionary Studies of Biosystems, SOKENDAI (Graduate University for Advanced Studies), Hayama, Japan

f. Comparative Medicine Institute, North Carolina State University, Raleigh, NC, USA

g. Center for Human Health and the Environment, North Carolina State University, Raleigh, NC, USA

\section{ORCID IDs:}

Alex Dornburg:

0000-0003-0863-2283

Dustin J. Wcisel:

0000-0001-6858-643X

Katerina Zapfe:

0000-0002-5159-641X

Andrew W. Thompson:

0000-0002-1198-6130

Ingo Braasch:

0000-0003-4766-611X

Tatsuya Ota:

0000-0002-1115-5169

Jeffrey A. Yoder:

0000-0002-6083-1311

\section{${ }^{*}$ Corresponding authors at:}

Alex Dornburg, Department of Bioinformatics and Genomics, University of North Carolina at Charlotte, Charlotte, NC USA. E-mail address: adornbur@uncc.edu. Phone: +1 704-687-8437

Jeffrey A. Yoder, Department of Molecular Biomedical Sciences, North Carolina State University, 1060 William Moore Drive, Raleigh, NC 27607, USA. E-mail address:

jeff_yoder@ncsu.edu. Phone: +1 919-515-7406 


\section{Abstract}

Over $99 \%$ of ray-finned fishes (Actinopterygii) are teleosts, a clade that comprises half of all living vertebrates that have diversified across virtually all fresh and saltwater ecosystems. This ecological diversity raises the question of how the immunogenetic diversity required to persist under heterogeneous pathogen pressures evolved. The teleost genome duplication (TGD) has been hypothesized as the evolutionary event that provided the genomic substrate for rapid genomic evolution and innovation. However, studies of putative teleost-specific innate immune receptors have been largely limited to comparisons either among teleosts or between teleosts and distantly related vertebrate clades such as tetrapods. Here we describe and characterize the receptor diversity of two clustered innate immune gene families in the teleost sister lineage: Holostei (bowfin and gars). Using genomic and transcriptomic data, we provide a detailed investigation of the phylogenetic history and conserved synteny of gene clusters encoding diverse immunoglobulin domain-containing proteins (DICPs) and novel immune-type receptors (NITRs). These data demonstrate an ancient linkage of DICPs to the major histocompatibility complex (MHC) and reveal an evolutionary origin of NITR variable-joining (VJ) exons that predate the TGD by at least 50 million years. Further characterizing the receptor diversity of Holostean DICPs and NITRs illuminates a sequence diversity that rivals the diversity of these innate immune receptor families in many teleosts. Taken together, our findings provide important historical context for the evolution of these gene families that challenge prevailing expectations concerning the consequences of the TGD during actinopterygiian evolution.

Keywords. Bowfin and gar, multigene families, diverse immunoglobulin domain-containing proteins (DICPs), novel immune-type receptors (NITRs), V(D)J recombination, MHC 


\section{Introduction}

With over 33,000 species, teleost fishes are the most diverse clade of living ray-finned fishes (Actinopterygii). A hallmark of their diversification history is the ability to repeatedly colonize and radiate across virtually all of the planet's fresh and saltwater ecosystems (Seehausen 2006; Friedman et al. 2013; Davis et al. 2014; Price et al. 2014; Brawand et al. 2014; Dornburg et al. 2017; Salzburger 2018; Daane et al. 2019). While numerous studies have identified mechanisms that underlie teleost morphological and species diversification dynamics (Price et al. 2014; Sibert et al. 2018; Iglesias et al. 2018; Gajdzik et al. 2019; Near and Kim 2021), the role of the teleost genome duplication (TGD) (Braasch and Postlethwait 2012; Glasauer and Neuhauss 2014) event as a substrate that promoted the evolution of immunogenetic novelty in the early evolutionary history of teleosts remains unclear. On the one hand, investigations of teleost genomes have resulted in descriptions of several families of innate immune receptors putatively unique to teleosts (Yoder and Litman 2011; Montgomery et al. 2011; Rodríguez-Nunez et al. 2014; Wcisel and Yoder 2016; Traver and Yoder 2020). On the other, with very few exceptions (Boudinot et al. 2014; Conant 2020) most comparative immunogenetic studies have been limited to investigations among teleosts (Ferraresso et al. 2009; Rebl et al. 2010; Montgomery et al. 2011; Aoki et al. 2013; Pietretti and Wiegertjes 2014; Rodríguez-Nunez et al. 2014; Wcisel and Yoder 2016) or between teleosts and distantly related vertebrate clades such as tetrapods (Yoder and Litman 2011; Langevin et al. 2013; Kasahara and Flajnik 2019). These studies are of incredible value, but do not consider the potential sequence diversity within the few living non-teleost actinopterygians. Such a comparison is critical if we are to disentangle teleost-specific patterns of evolution from the overall sequence diversity and genomic architecture of the general ray-finned fish immune system.

The closest relatives to living teleosts are holosteans (Grande 2010; Near et al. 2012b; Braasch et al. 2016; Betancur-R et al. 2017; Wcisel et al. 2020; Hughes et al. 2018), vestiges of two clades of ancient fishes that flourished during the Mesozoic (Smithwick and Stubbs 2018). 
Recent sequencing of both the spotted gar (Lepisosteus oculatus) (Braasch et al. 2016) and the bowfin (Amia calva) genomes (Thompson et al. 2021) found that portions of the genomes of these fishes demonstrate surprising conservation with elements from tetrapods, thereby revealing likely characteristics of early bony vertebrate genomes. For example, the bowfin genome revealed an extensive linkage of $\mathrm{MHC}$ class I, class II and class III loci (Thompson et al. 2021), a condition found in humans but not observed in any teleost fish and unresolved in gar (Braasch et al. 2016; Yamaguchi and Dijkstra 2019). Moreover, clusters of diverse immunoglobulin-domain containing proteins (DICPs) are encoded within the MHC locus of bowfin. DICPs have been identified in teleosts, holosteans, and coelacanth and possess one or more extracellular Ig domains that fall into two types termed D1 and D2 (Haire et al. 2012; Boudinot et al. 2014; Rodriguez-Nunez et al. 2016; Wcisel and Yoder 2016; Gao et al. 2018). In zebrafish, DICPs are expressed by lymphocytes and myeloid cells, are predicted to play important roles in pathogen recognition, and may regulate interferon signaling (Haire et al. 2012; Carmona et al. 2017; Gao et al. 2018). In bowfin, these multigene clusters are surrounded by well-conserved genes whose synteny can be traced to both teleost (zebrafish) and tetrapod (human) genomes (Thompson et al. 2021). As such, investigating the evolutionary history of these gene clusters may help illuminate core motifs of the ancestral, ('proto' or 'Ur'), vertebrate MHC (Abi Rached et al. 1999; Kasahara 1999).

In addition to loci associated with the MHC locus, the spotted gar genome revealed the first evidence for the existence of novel immune-type receptors (NITRs) outside of teleosts (Braasch et al. 2016; Wcisel et al. 2017). NITR clusters have been identified in all examined teleost lineages (Strong et al. 1999; Yoder et al. 2004; Desai et al. 2008; Yoder 2009; Ferraresso et al. 2009; Wcisel and Yoder 2016) and are predicted to function as natural killer cell receptors (Litman et al. 2001; Yoder et al. 2010). Typically, NITRs possess two extracellular Ig domains, one membrane-distal variable (V)-like domain and one membrane-proximal intermediate (I)-like domain. The majority of NITR V and I domains include a C-terminal joining 
(J)-like sequence. Given that the V-J and I-J sequences are encoded in single exons with no evidence for recombination, this raises the possibility that NITRs are derived from the progenitor receptor sequences that gave rise to $\mathrm{VJ}$ and subsequently VDJ recombination in Immunoglobulin (Ig) and T-Cell Receptor (TCR) genes of the adaptive immune system of jawed vertebrates (Yoder 2009). In the absence of a detailed analysis of holostean NITRs, it remains unclear whether the origin of their diversity aligns with or predates the origin of teleosts and the TGD.

NITRs and DICPs also share similarities beyond possessing extracellular lg domains. An additional unifying feature of the DICP and NITR families is the inclusion of inhibitory, activating, secreted and functionally ambiguous forms (Wcisel and Yoder 2016). Inhibitory DICPs and NITRs encode one or more cytoplasmic immunoreceptor tyrosine-based inhibition motif (ITIM; S/I/V/LxYxxI/V/L) or ITIM-like sequences (itim), whereas activating receptors possess an intramembranous charged residue permitting association with activating adaptor proteins (e.g. Dap12) (Wei et al. 2007; Wcisel and Yoder 2016). Both receptor families also include secreted forms that lack a transmembrane domain and functionally ambiguous forms that possess a transmembrane domain, but lack any identifiable signaling motif. However, whether all of these different functional forms are represented in holosteans or if some are restricted to teleosts remains to be determined.

Here we integrate phylogenetic, genomic, and transcriptomic analyses of the spotted gar and bowfin DICPs and NITRs. We begin by providing the first description of the diversity of NITRs and DICPs across holosteans, illuminating evidence for functionally analogous sequences between the deeply divergent lineages of gar and bowfin. We then use phylogenetic approaches to estimate the evolutionary history of each receptor family across the common neopterygian fish ancestor of holosteans and teleosts. This allowed us to test whether the TGD is correlated with higher receptor diversity in teleosts versus equivalent signatures of diversification within holosteans. We then assess patterns of conserved synteny between 
holostean receptor families, allowing us to assess the degree to which gene regions surrounding holosteans are syntenic to those of teleosts. Collectively, our findings provide the historical framework necessary to contextualize changes of these receptor families in teleosts and neopteryigans. More broadly, these findings provide a new perspective for future work concerning the consequences of the TGD on teleost fish immunogenetic receptor diversity.

\section{Methods}

Overview of the bowfin genome

Our analysis is based on the recently published bowfin genome that contains 1,958 scaffolds and 23 pseudochromosomes (named Aca_scaf_1 through Aca_scaf_23) that contain $99 \%$ of the assembly and match bowfin's chromosome number (Thompson et al. 2021). These pseudochromosomes are consistent with a chromosome-level genome assembly, but have not yet been definitively assigned to individual chromosomes. As such, we retain the Aca_scaf nomenclature in this manuscript. Genes in the bowfin genome were annotated using the MAKER genome annotation software (Holt and Yandell 2011), reporting a total of approximately 22,000 protein-coding genes (Thompson et al. 2021). This gene annotation applied the prefixes AMCG (AMia Calva Gene) and AMCP (AMia Calva Protein). We refined these predictions in our delimitation of bowfin DICP and NITR sequences.

\section{Bowfin DICP and NITR nomenclature}

Bowfin DICP and NITR sequences were named consecutively: dicp1, dicp2, dicp3 etc., and nitr1, nitr2, nitr3 etc. Putative pseudogenes were assigned the next number in the symbol series and suffixed by a "p". Sequences were considered pseudogenes if a predicted exon 
possessed an internal stop codon or if a solitary exon was identified. It is emphasized that due to recent lineage-specific diversification of the DICP and NITR families, one-to-one genetic orthologs are not identifiable between species, and gene names reflect only the order in which they were identified. For example medaka NITR1a is not a "true" ortholog of either zebrafish nitr1a or pufferfish NITR1 (Desai et al. 2008).

Identification of bowfin DICP genes and transcripts

The identification and organization of bowfin genes dicp1 through dicp20 on Aca_scaf_14 was reported previously (Thompson et al. 2021). Note that the genome sequence of the dicp18p pseudogene can only encode a partial lg domain (32 residues) (Thompson et al. 2021) for which additional analyses are not possible. As such, we excluded this gene from all analyses below. tBLASTn searches of the bowfin reference genome were conducted using spotted gar DICP Ig domain sequences as queries to search for additional DICPs in other regions of the bowfin genome. BLAST searches of publicly available bowfin RNA-seq (Supplementary Note 1) were used to identify DICP transcripts. Specifically, tBLASTn searches (E value cutoff $E-6)$ of bowfin transcript sequences available through the PhyloFish database (http://phylofish.sigenae.org/) (Pasquier et al. 2016) and bowfin transcriptome data from the immune tissues of a single adult fish (bowfin 0039) (Thompson et al. 2021) were conducted using spotted gar DICP Ig domain sequences as queries. Syntenic relationships between bowfin and gar were determined using reciprocal BLASTp searches against the spotted gar genome. To ensure genes with multiple isoforms were only represented by one protein sequence, only the first protein sequence encountered in the annotation file for each genome was used in the BLAST analysis. The results of the BLAST searches were subjected to collinear analyses using MCScanX (Wang et al. 2012). 
Identification of bowfin NITR genes and transcripts

In our initial search of the bowfin genome-predicted proteins (e.g. AMCP sequences) for NITR sequences, we employed spotted gar NITR I domains (Wcisel et al. 2017) as queries for BLASTP searches (e value cutoff $<1 \mathrm{e}-15$ ) as the high rate of sequence evolution in NITR V domains limits their utility for effective homology searches over deep evolutionary time scales. In order to identify bowfin NITR transcripts, we used the candidate NITR sequences encoded by the genes described above and all reported spotted gar NITR I domains (Wcisel et al. 2017) as queries for tBLASTn searches (e values <1e-10) against immune tissue RNA-seq from bowfin 0039 (Thompson et al. 2021) and from bowfin available from PhyloFish (Pasquier et al. 2016)

(Supplementary Note 1). Resultant protein sequences were manually inspected and those lacking an Ig domain or found to encode Ig light chain proteins were excluded. Remaining sequences were trimmed to remove untranslated sequences.

Reanalyses of the bowfin NITR cluster

As our pilot analysis indicated the presence of multiple I domains in individual predicted bowfin AMCP proteins (which would be an unprecedented NITR protein architecture), we reanalyzed the delimitation of bowfin NITRs using all identified bowfin I domain peptide sequences as queries for tBLASTn searches (e values <1e-10) of the reference genome. Sequences that did not possess at least four of the six conserved cysteines within the I domain were removed. We replicated these tBLASTn searches to identify additional NITR V domains, but restricted sequences to those with a corresponding I domain in close genomic proximity. We combined all candidate NITR nucleotide sequences from the genomic and transcriptomic searches into Splign (Kapustin et al. 2008) to map all possible exons from genes and transcripts. This allowed us to manually link adjacent NITR exons into individual NITR genes 
and create a genomic map of the NITR gene cluster. Exonic maps were generated using the ggplot 2 package (Wickham 2011) in R 4.0.2. Syntenic relationships were determined as for DICPs.

\section{Protein sequence analyses}

Protein domains were identified using SMART (Letunic and Bork 2018) and SignalP (Almagro Armenteros et al. 2019). Protein sequences from bowfin were compared to DICP or NITR sequences from spotted gar (Wcisel et al. 2017) and representative teleosts in which these receptors had previously been described [zebrafish (Danio rerio), carp (Cyprinus carpio and Ctenopharyngodon idella), pufferfish (Takifugu rubripes and Sphoeroides nephelus), salmon (Salmo salar), medaka (Oryzias latipes), and tilapia (Oreochromis niloticus) (Strong et al. 1999; Yoder et al. 2004, 2008; Desai et al. 2008; Haire et al. 2012; Rodriguez-Nunez et al. 2016)]. In addition, a candidate DICP from coelacanth (Latimeria chalumnae) was included (Boudinot et al. 2014). Sequences were aligned using Clustal Omega (Sievers and Higgins 2018) or MAFFT (Katoh and Standley 2014; Nakamura et al. 2018). Boxshade (version 3.21) alignment plots were made using the MAFFT-based alignment and manually annotated (https://embnet.vital-it.ch/software/BOX form.html).

To determine the best-fit model of amino-acid substitution and infer a maximum likelihood phylogeny of DICP and NITR Ig domains, the alignment of each sequence was analyzed using IQ-TREE (Nguyen et al. 2015; Kalyaanamoorthy et al. 2017). The candidate pool of substitution models spanned all common amino acid exchange rate matrices (e.g., JTT (Jones et al. 1992), WAG (Whelan and Goldman 2001) to protein mixture models such as empirical profile mixture models (Quang et al. 2008), and also included parameters to accommodate among site rate variation (e.g., discrete gamma (Yang 1994) or a free rate model (Soubrier et al. 2012). The best-fit substitution model for each alignment was selected using 
Akaike information criterion in IQ-TREE (Nguyen et al. 2015; Kalyaanamoorthy et al. 2017). Node support was assessed via 1,000 ultrafast bootstrap replicates (Minh et al. 2013; Hoang et al. 2018).

\section{Results and Discussion}

\section{Bowfin DICPs are embedded within the MHC}

We recently reported two DICP gene 'clusters' on bowfin pseudochromosome Aca_scaf_14 (Fig. 1a) (Thompson et al. 2021) and our blast searches of the bowfin genome identified an additional pseudogene dicp21p on pseudochromosome Aca_scaf_11 with no support for synteny with known DICPs in other species. We previously reported multiple DICP sequences from the spotted gar genome that are encoded on multiple genomic scaffolds (Wcisel et al. 2017) that our results demonstrate to share synteny with the Aca_scaf_14 DICP cluster (Fig. 1b) suggesting they might be linked in gar as well. We report twenty different bowfin DICP genes and pseudogenes (dicp1 - dicp20) encoded in a cluster within the extended MHC region (that includes MHC class I, class II and class III genes) on Aca_scaf_14 (Fig. 1a-b and Supplementary Table S1). This linkage of DICPs to the MHC in bowfin sheds light on our previous finding that zebrafish DICPs are tightly linked to MHC class I genes (Rodriguez-Nunez et al. 2016). These results in bowfin reveal that it is likely that in early diverging ray-finned fishes, DICPs were encoded within an extended MHC region (including class I, II, and III genes). Following the TGD, this linkage was likely fragmented through the heterogeneous maintenance of duplicated MHC gene clusters on different chromosomes.

Teleost DICP genes typically encode at least five exons with the first four encoding a signal peptide sequence, a D1-type Ig domain, a D2-type Ig domain, and a transmembrane domain with subsequent exons encoding a cytoplasmic tail, although a few DICP genes encode 
four extracellular domains with a D1a-D2a-D1b-D2b organization (Haire et al. 2012). Our results demonstrate that many bowfin DICPs encode a similar number of exons as teleosts (Fig. 1c and Supplementary Table S1). Although not all bowfin DICP genes can be confirmed to encode functional proteins (e.g. dicp15p and dicp17p were each identified as encoding a single transmembrane exon), at least eleven bowfin genes (dicp2, dicp4, dicp5, dicp6, dicp10, dicp11, dicp12, dicp14, dicp16, dicp19 and dicp20) are predicted to encode functional DICPs (see below).

Bowfin DICP Ig domain architectures mirror those of teleosts

The majority of DICPs in teleosts and spotted gar have been characterized by the presence of four conserved cysteines in their extracellular lg domains, D1 and D2 (Haire et al. 2012; Rodriguez-Nunez et al. 2016; Wcisel et al. 2017; Gao et al. 2018). Two of these cysteines $\left[\mathrm{C}^{23}\right.$ and $\mathrm{C}^{104}$, numbering based on the IMGT system (Lefranc et al. 2015)] likely play roles in stabilizing each Ig-fold (Williams and Barclay 1988). It has been suggested that the other, DICPspecific cysteines might promote DICP dimerization (Rodríguez-Nunez et al. 2014; Wcisel et al. 2017). Consistent with this expectation, we find that dicp6, dicp10, dicp11, dicp14, dicp 16 and dicp20, which likely encode proteins with a D1-D2 structure, possess all four conserved cysteines (Figs. 2 and 3). In contrast, dicp2, dicp5, dicp12 and dicp19, which are predicted to encode proteins with a D1a-D2a-D1b-D2b structure, possess $C^{23}$ and $C^{104}$, but lack the majority of the DICP-specific cysteines. This subtle difference may indicate D1-D2 DICPs may be more likely to dimerize than D1a-D2a-D1b-D2b DICPs. Phylogenetic analyses of the bowfin DICP D1 and D2 domains support monophyly for the majority of the D1b and D2b domains (Fig. 4). This suggests a single early origin of the D1a-D2a-D1b-D2b motif with a subsequent loss of the D1bD2b architecture in DICPs such as dicp6, dicp9, and dicp11. A possible mechanism for such an origin could be the loss of a transcription terminator signal from the upstream gene and the loss 
of a signal peptide from an adjacent downstream gene. Such a loss, along with alternative mRNA splicing, could facilitate the transcription of additional extracellular lg domains in a single gene. Although speculative, such an event could also explain the finding of a D1a-D2a-D1b-D2b structure in zebrafish. The presence of this duplicated domain structure in bowfin suggests that repeating domain organization such as the D1a-D2a-D1b-D2b structure can arise from the clustered nature of gene families, rather than relying on major evolutionary events such as the TGD to provide a substrate for innovation.

Bowfin DICP diversity is not the result of a lineage-specific expansion

All DICP Ig domains identified from the bowfin reference genome can be classified as either a D1 or D2 based on strong phylogenetic support [Bootstrap support (BSS) = 100]. Our phylogenetic analyses based on Ig domains from bowfin, aligned to DICP D1 and D2 domains from zebrafish, carp, salmon, pufferfish, tilapia, spotted gar and coelacanth, place the evolutionary history of holostean DICPs and the pairing of D1 and D2 domains into the broader context of vertebrate DICPs (Fig. 4). Within teleosts, the most detailed work on DICPs has been conducted within cyprinids (e.g., zebrafish, carp; Haire et al. 2012; Rodriguez-Nunez et al. 2016; Gao et al. 2018). It has been hypothesized that clusters of teleost DICP genes arose as a consequence of within-clade tandem gene duplication, largely through species-specific diversification (Haire et al. 2012), a result also supported by our phylogenetic analyses (Fig. 4). Holosteans depart from this pattern. Within each clade of holostean DICPs, intraspecific gene diversification events are less frequent than those observed in cyprinds. Instead, each DICP clade comprises a few gar and bowfin genes with no support for a monophyletic cluster of holostean genes (Fig. 4). Given that we have investigated the genomes of bowfin and spotted gar as well as a range of bowfin transcriptomes (see below), it is unlikely we have missed major clusters of DICPs. These results suggest that the DICP evolution in holosteans contrasts with 
that of teleosts such as zebrafish. Furthermore, gar and bowfin diverged several hundred million years ago (Near et al. 2012b; Dornburg et al. 2014; Hughes et al. 2018), a divergence on par with that of birds and crocodiles (Nesbitt 2003; Alfaro et al. 2009; Prum et al. 2015; Fabbri et al. 2017). This divergence, coupled with the observation that holosteans appear to have some of the slowest rates of molecular evolution among vertebrates (Braasch et al. 2016; Takezaki 2018) suggests that rather than a consequence of within-species diversification, DICP diversity in living holosteans is the result of maintaining a diversity of genes with ancient evolutionary origins.

Bowfin DICP transcripts predict inhibitory, activating, secreted and functionally ambiguous protein structures

The 21 DICP sequences predicted from the bowfin reference genome include seven genes predicted to possess an extracellular D1-D2 organization and four genes predicted to possess an extracellular D1a-D2a-D1b-D2b organization (Fig. 5) with the remaining DICP genes reflecting partially annotated genes or pseudogenes (Supplementary Table S1 and Fig. S1). Two of the eleven predicted bowfin DICPs possess a cytoplasmic ITIM indicating a likely inhibitory function, whereas four DICPs possess a charged residue within their transmembrane reflective of an activating function, and five DICPs lack any identifiable signaling motif.

In an effort to validate these predicted protein structures, BLAST searches of publicly available bowfin transcriptomes (Supplementary Note 1) were conducted and nine distinct transcripts identified (Fig. 5 and Supplementary Table S2 and Fig. S2). Specifically, tBLASTn searches identified five predicted bowfin DICP transcripts on the PhyloFish database (“DICP3.3.1.1”, LOC100536667.1.1, LOC100333982.1.2, LOC100333982.2.2, and PTC1.1.2) and revealed four distinct bowfin DICP transcripts from bowfin 0039 (1382_c24_g1_i1, 1382_c24_g1_i5, 1382_c35_g3_i1 and 1382_c35_g3_i5). All nine transcripts encode either a 
D1-D2 or D1a-D2a-D1b-D2b organization which is reflective of most cyprinid DICPs, although D1-only DICPs have been described from zebrafish and carp (Haire et al. 2012; Gao et al. 2018). As with teleost DICPs, bowfin DICPs include inhibitory, activating, secreted and functionally ambiguous forms.

DICP sequence diversity indicates gene content variation

Gene content variation and alternative mRNA splicing appear to contribute to bowfin DICP diversity. None of the bowfin DICP transcripts mapped onto the reference genome with $100 \%$ accuracy. As the reference genome and transcriptome sequences were derived from different individuals, this observation indicates intraspecific DICP sequence variation in bowfin as described in zebrafish (Rodriguez-Nunez et al. 2016). Nevertheless, a phylogenetic comparison of transcript-encoded DICP D1 and D2 domains to genome-encoded D1 and D2 domains revealed multiple similarities (Supplementary Fig. S3). Direct comparisons of highly similar sequences suggest that certain DICP transcripts may reflect polymorphic versions of specific DICP genes and indicate that alternative mRNA splicing can also contribute to DICP diversity (summarized in Fig. 5 with details provided in Supplementary Note 2 and Figs. S4S9).

The number of bowfin NITR genes rivals that of teleosts

We previously reported fifteen distinct NITR sequences that occur within two genomic regions of the spotted gar genome (Braasch et al. 2016). We expanded this by identifying two additional gar NITR sequences (Fig. 6a) (Wcisel et al. 2017). Here we report a total of 34 bowfin NITR genes and pseudogenes (nitr1 - nitr34) encoded across pseudochromosome Aca_scaf_8 and six unplaced scaffolds (Supplementary Table S3). The cluster on Aca_scaf_8 encodes the 
largest number of NITRs (nitr1 - nitr28) in two clusters spanning approximately 313 Kbp and 42 Kbp (Fig. 6a). Each of the six smaller scaffolds that encode NITR sequences [Aca_scaf_68 (7420 bp), Aca_scaf_85 (5,185 bp), Aca_scaf_148 (3,624 bp), Aca_scaf_149 (3,603 bp), Aca_scaf_657 (1,711 bp), and Aca_scaf_1322 (1,237 bp)] encode one additional NITR. Teleost and gar NITRs genes typically encode several defining regions: a signal peptide sequence, a Vtype Ig domain, an I-type Ig domain, J segments, a transmembrane domain with subsequent exons encoding a cytoplasmic tail (Yoder 2009). Our results demonstrate that many bowfin NITRs encode similar regions (Fig. 6b and Supplementary Table S3).

Although not all bowfin NITR genes can be confirmed to encode functional proteins (e.g. pseudogenes nitr9p and nitr30p encode an internal stop codon or frameshift within the $\mathrm{V}$ domain and nitr10p and nitr11p encode partial I domains), at least six genes (nitr2, nitr16, nitr20, nitr21, nitr24, and nitr34) are predicted to encode both a $\mathrm{V}$ and I domain and are considered functional NITRs (see below and Supplementary Table S3 and Fig. S10). Because nitr27 encodes a $\mathrm{V}$ domain with only part of an I domain (it is missing the C-terminal region of the I domain including the highly conserved $\mathrm{C}^{104}$ that stabilizes the $\mathrm{Ig}$ fold), we exclude it from phylogenetic analyses of I domains. Due to the large number of ambiguous base $(\mathrm{N})$ assignments in the assembly, several partial NITR genes (encoding 1 or 2 exons) were identified in Aca_scaf_8 that may reflect pseudogenes or partial genes (e.g. nitr3, nitr7, nitr8, nitr13, etc.) Nevertheless, the identification of 34 NITR sequences in bowfin is on par with the 39, 44 and 30 NITR genes identified in zebrafish, medaka and sea bass, respectively (Yoder et al. 2004; Desai et al. 2008; Ferraresso et al. 2009; Rodriguez-Nunez et al. 2016) suggesting that the large number of teleost NITRs is not just a result of paralog retention following the TGD.

NITRs are likely derived from an ancient gene family that gave rise to $V(D) J$ recombination 
Teleost and gar NITR V domains are highly similar to TCR and lg gene V domains. However, in both lineages NITR I domains possess six highly conserved cysteines (two cysteines that form the disulfide bond promoting the Ig-fold and four novel cysteines that have not been identified in any other class of Ig domain-containing protein family) that provide a means to distinguish NITRs from TCR and Ig genes (Yoder 2009; Wcisel and Yoder 2016) (Fig. 7). We demonstrate that bowfin NITR Ig domains possess an architecture similar to other NITR $\mathrm{V}$ and I domains. Alignment-based comparisons between bowfin, gar, and teleost $\mathrm{V}$ domains (Fig. 8) reveals the presence of residues that are conserved across NITR, T-cell receptor (TCR) and Immunoglobulin Ig domains such as $C^{23}$ and $C^{104}$ (Litman et al. 2001; Yoder 2009). In comparison to the $\mathrm{V}$ domains, the alignment of the bowfin I domains reveals striking withinspecies sequence conservation (Fig. 7) We also find that about half of bowfin NITR V domains and the majority of the NITR I domains possess nearly perfect germ-line joined consensus $\mathrm{J}$ sequences, FGxGTxLx(V/L).

The presence of $\mathrm{J}$ or $\mathrm{J}$-like sequences in a single exon with a $\mathrm{V}$ or I domain is characteristic of teleost NITRs, and supports the proposal that NITRs either represent an ancient gene family that may have given rise to $V(D) J$ recombination in the adaptive immune system, or an evolutionary novelty that arose as a consequence of the teleost genome duplication (Strong et al. 1999; Litman et al. 2001, 2003; Yoder et al. 2004). The hypothesis that NITRs arose as a consequence of the TGD was supported by the lack of evidence for NITR homologs in cartilaginous fishes (Yoder et al. 2004). However, our finding of V-J and I-J motifs in both species of holosteans rejects this TGD-derived hypothesis. Instead, NITRs are in fact an ancient family of innate immune receptors with origins that predate the TGD. Future investigations focused on the origins of NITRs are needed to determine if this gene family is unique to neopterygians, or represents an older gene family that has been maintained in rayfinned fishes but subsequently lost in sarcopterygians. 
Holostean NITR diversity is derived from lineage specific expansions

Although NITR's may represent an ancient gene family, NITR sequence diversity appears largely species-specific, meaning any individual NITR sequence is generally more similar to another NITR sequence from within the same species than another (Desai et al. 2008; Yoder 2009; Ferraresso et al. 2009). Our phylogenetic analyses place bowfin NITR diversity within the broader context of neopterygian sequences and support this hypothesis. Analysis of the I domain reveals that the vast majority of bowfin NITRs are monophyletic. The sole exception is Nitr2, which is resolved as the sister lineage (BSS $=91$ ) to a well-supported clade $(B S S=97)$ that contains all spotted gar NITRs. In both holosteans and teleosts, within-species receptor diversity largely evolved in situ (Fig. 9). However, the in situ diversification of gar and bowfin NITR I domains represents a dramatic shift towards estimated branch lengths smaller than those estimated in teleosts. This contrast is of particular note as the estimated time of divergence between gar and bowfin is either similar to or slightly exceeds the time to common ancestry for the teleosts in this study (Near et al. 2012b; Dornburg et al. 2014; Hughes et al. 2018). This contrast between holostean and teleost branch lengths is also evident in a phylogenetic analysis of $\mathrm{V}$ domains (Fig. 10). Given the high rate of sequence evolution in NITR V domains versus I domains, our phylogenetic analyses reveal numerous cases of likely evolutionary convergences in V-domain sequence similarity between teleosts as well as teleosts and holosteans (Fig. 10). These results raise the question of whether the teleost genome duplication catalyzed faster rates of molecular evolution in teleosts, or if other mechanisms underlie the slow rates of sequence evolution that characterize holosteans (Braasch et al. 2016). We hope to address this question in the future with a broader sampling of species and innate immune receptors.

Predicted functional diversity in bowfin NITRs matches that of teleosts 
Of the 34 NITR sequences we manually predicted and annotated from the bowfin reference genome six are predicted to possess an extracellular V-I organization (Fig. 11a and Supplementary Fig S10.) with the remaining NITR genes reflecting partially annotated genes or pseudogenes (Supplementary Table S3). The majority of the sequences identified by automated prediction software do not reflect NITR protein architecture described in teleosts and are not supported by transcriptome data (below). The one exception is AMCP00014119 that is predicted to encode a bonafide NITR (Nitr27), albeit with a truncated I domain.

As described for DICPs, we searched for bowfin NITR transcripts with BLAST searches of publicly available bowfin transcriptomes (Supplementary Note 1) and 26 distinct transcripts were identified (Fig. 11b-c and Supplementary Table S4 and Fig. S11). Fourteen of these transcripts encode both a $\mathrm{V}$ and an I domain which reflects what is predominantly observed in teleosts (Litman et al. 2001; Yoder 2009; Ferraresso et al. 2009). One transcript, 7779_c0_g1_i4 is truncated but predicted to encode an activating NITR by the presence of a charged residue within the transmembrane domain (Fig. 11b and Supplementary Fig. S11). The majority of the other bowfin NITR transcripts with both $\mathrm{V}$ and I domains encode ITIM- or itim-like sequences and are considered inhibitory receptors. As V-only NITR genes have been described in some teleosts (Yoder et al. 2004; Desai et al. 2008; Ferraresso et al. 2009), and an alternatively spliced I-only NITR has been described in zebrafish (Shah et al. 2012), we report similar bowfin transcripts in Supplementary Table S4 and Fig. S11. As with teleost NITRs, bowfin NITRs appear to include inhibitory, activating, secreted and ambiguous forms.

NITR sequence diversity indicates gene content variation

Gene content variation appears to contribute to bowfin NITR diversity. As with DICPs, none of the bowfin NITR transcripts mapped onto the reference genome with $100 \%$ accuracy. A 
phylogenetic comparison of transcript-encoded NITR $\mathrm{V}$ domains to genome-encoded $\mathrm{V}$ domains revealed multiple similarities (Supplementary Fig. S12), however, only eight of 26 bowfin transcripts could be mapped back onto the reference genome with some level of certainty (Supplementary Note 3, Table S4 and Figs. S11, S13-S15). As described in Supplementary

Note 1, the reference genome and transcriptome sequences were derived from different individuals indicating that bowfin NITRs, like zebrafish NITRs and bowfin DICPs (see above), display intraspecific gene content variation. More specifically, all eight of these transcripts were derived from a single bowfin (0039) that was collected near the geographic location where the individual used for the reference genome was collected (Supplementary Note 1) (Thompson et al. 2021).

\section{Summary: Considering DICPs and NITRs in the context of the TGD}

Over the past several decades, numerous ray-finned fish genes and gene families have been hypothesized to be teleost-specific due to the lack of reference genomes for the few living species of non-teleost ray-finned fishes and the absence of these genes in more distantly related sarcopterygians (lungfish, coelacanth, tetrapods) or earlier diverging non-bony vertebrates (lamprey, hagfish, chondrichthyans). However, the continued sequencing of nonteleost ray-finned fishes provides us with an exciting opportunity to test expectations of TGDcatalyzed innovation and contextualize general principles of genome evolution. Our results illuminate the functional diversity of NITR and DICP receptors in bowfin (Figs. 5 and 11), suggesting that high functional diversity of these receptors represent a hallmark of neopterygians if not actinopterygians more generally. These findings do not support the hypothesis that the TGD catalyzed a sudden burst of evolutionary novelty that gave rise to new teleost fish innate immune receptor families. Instead, this diversity was already in place and likely has far more ancient origins within ray-finned fishes. 
Combining our results with other investigations of the bowfin and gar genomes (Braasch et al. 2016; Wcisel et al. 2017; Thompson et al. 2021), it is evident that rather than catalyze a pulse of molecular diversification, the TGD likely had a dramatic impact on the overall architecture of the teleost genome that may have provided the substrate for subsequent withinlineage diversification. We find that the DICP genes are located within two closely positioned clusters on the same pseudochromosome (Aca_scaf_14) as gene clusters of MHC class I lineages (U, Z, P, and L) as well as MHC class II and class III genes, even though some MHC I class I genes (P, L, S and $\mathrm{H}$ lineages) are present on other pseudochromosomes. This condition contrasts with that of teleost fishes such as zebrafish where a cluster of DICP genes is linked to a cluster of MHC class I Z lineage genes, and U lineage genes are on other chromosomes (Dirscherl et al. 2014; Rodriguez-Nunez et al. 2016). Our results suggest that the fragmentation of MHC class I/II/III genes and DICP genes in teleosts arose due to differential loss of genes from paralogous chromosomes in combination with post-TGD chromosomal rearrangements. Additional evidence for this hypothesis is found in Aca_scaf_8: here bowfin NITR genes are intermingled with other Ig-domain containing proteins such as CD276-like (AMCP00014071) and NCAM2-like sequences (AMCP00014072, AMCP00014074, AMCP00014075, AMCP00014076) (Fig. 6A). Conserved gene synteny between spotted gar linkage group 14 and bowfin Aca_scaf_8 is observed, exemplified by the presence of a cluster of olfactory receptor (OR) genes as well as a number of single copy genes (e.g. runx1, DONSON, etc). This synteny is noteworthy, as the NITR region of the spotted gar genome was not found to be syntenic with model teleosts such as zebrafish thereby suggesting a loss of synteny between the NITR loci of teleosts and holosteans following the TGD.

Collectively, our results align with an emerging perspective concerning the fate of paralogs in genome evolution that predicts paralog diversity to rarely be maintained over deep stretches of evolutionary time (Nei and Rooney 2005; Ferraresso et al. 2009; Inoue et al. 2015; Fernández and Gabaldón 2020). There is little reason to expect that a sudden shift in the 
diversification of a gene family should occur in the absence of an external catalyst that imposes strong selective pressures. Instead it is far more likely that the clustered organization of these and similar families of innate immune receptors have, and continue to provide the genomic substrate required to persist in the face of evolving pathogenic threats over several hundred million years of teleost evolution. The changes in pathogen driven selective pressures as rayfinned fishes have made evolutionary transitions to novel biomes such as saltwater to freshwater transitions (Yamanoue et al. 2011; Nakatani et al. 2011; Davis et al. 2012), invaded new adaptive zones (Dornburg et al. 2011; Burns and Sidlauskas 2019; Friedman et al. 2019), or faced changes in climatic conditions (Near et al. 2012a; Siqueira et al. 2019), could be associated with pathogenic spread. Transitions such as these may explain the high withinlineage diversity of these receptor families. In particular, it is possible that these clusters are hot spots for gene birth and death, which could provide the mechanism for our observations of intraspecific gene content variation. Although the diversification dynamics of these gene clusters remain unknown, inter-individual variation in gene content would provide a wider degree of protection to the next unknown pathogen (Uhrberg et al. 2002; Vilches and Parham 2002; Tukwasibwe et al. 2020) that at the level of meta-populations could mitigate the impact of novel pathogens during such evolutionary events. As we expand our ability to move detailed comparative genomic studies from the root of the teleost phylogeny to the tips, testing how such shifts in ecological opportunities often associated with the diversification of lineages (Near et al. 2013; Berv and Field 2018) and key ecological phenotypes (Salzburger 2018; Daane et al. 2019) has shaped the genomic basis of ray-finned fish immunity represents an exciting research frontier.

Acknowledgments. We thank Thomas Near (Yale University) for helpful discussions about bowfin biology and the consequences of the teleost genome duplication and Madhusudhan Gundappa (@fish_lines) for illustrations of bowfin and spotted gar. 
Funding. This research was supported, in part, by grants from the National Science Foundation (IOS-1755242 to AD and IOS-1755330 to JAY), a grant from the Triangle Center for Evolutionary Medicine (TriCEM) to AD and JAY, and funding from the National Institutes of Health (R01OD011116 to IB). The funding bodies played no role in the design of the study and collection, analysis, and interpretation of data and in writing the manuscript.

Authors' contributions. AD and JAY conceived of and designed the study. EF, KZ, AWT, IB, LRA, TO, DJW, and AWT assembled sequence data. AD, JAY, TO, EF, LRA, KZ, AWT, IB, and DJW analyzed the data. AD and JAY wrote the first draft of the manuscript. All authors contributed to the writing of the final manuscript.

Conflict of interest. The authors declare that they have no competing interests.

Data availability. All data used in this study are publicly available on NCBI, Ensembl, or the PhyloFish database (http://phylofish.sigenae.org/). Publicly available bowfin sequences accessed during this study are also provided as full length fasta formatted sequences and partitioned sequences linked to the delimitations of domains (e.g., NITR-I, NITR-V, etc) in the Supplementary Materials. 


\section{References}

Abi Rached L, McDermott MF, Pontarotti P (1999) The MHC big bang. Immunol Rev 167:33-44

Alfaro ME, Santini F, Brock C, et al (2009) Nine exceptional radiations plus high turnover explain species diversity in jawed vertebrates. Proc Natl Acad Sci U S A 106:13410-13414

Almagro Armenteros JJ, Tsirigos KD, Sønderby CK, et al (2019) SignalP 5.0 improves signal peptide predictions using deep neural networks. Nat Biotechnol 37:420-423

Aoki T, Hikima J-I, Hwang SD, Jung TS (2013) Innate immunity of finfish: primordial conservation and function of viral RNA sensors in teleosts. Fish Shellfish Immunol 35:1689-1702

Berv JS, Field DJ (2018) Genomic Signature of an Avian Lilliput Effect across the K-Pg Extinction. Syst Biol 67:1-13

Betancur-R R, Wiley EO, Arratia G, et al (2017) Phylogenetic classification of bony fishes. BMC Evol Biol 17:162

Boudinot P, Zou J, Ota T, et al (2014) A tetrapod-like repertoire of innate immune receptors and effectors for coelacanths. J Exp Zool B Mol Dev Evol 322:415-437

Braasch I, Gehrke AR, Smith JJ, et al (2016) The spotted gar genome illuminates vertebrate evolution and facilitates human-teleost comparisons. Nat Genet 48:427-437

Braasch I, Postlethwait JH (2012) Polyploidy in Fish and the Teleost Genome Duplication. Polyploidy and Genome Evolution 341-383

Brawand D, Wagner CE, Li YI, et al (2014) The genomic substrate for adaptive radiation in African cichlid fish. Nature 513:375-381

Burns MD, Sidlauskas BL (2019) Ancient and contingent body shape diversification in a hyperdiverse continental fish radiation. Evolution 73:569-587

Carmona SJ, Teichmann SA, Ferreira L, et al (2017) Single-cell transcriptome analysis of fish immune cells provides insight into the evolution of vertebrate immune cell types. Genome Res 27:451-461

Conant GC (2020) The lasting after-effects of an ancient polyploidy on the genomes of teleosts. PLoS One 15:e0231356

Daane JM, Dornburg A, Smits $P$, et al (2019) Historical contingency shapes adaptive radiation in Antarctic fishes. Nat Ecol Evol 3:1102-1109

Davis AM, Unmack PJ, Pusey BJ, et al (2012) Marine-freshwater transitions are associated with the evolution of dietary diversification in terapontid grunters (Teleostei: Terapontidae). $J$ Evol Biol 25:1163-1179

Davis MP, Holcroft NI, Wiley EO, et al (2014) Species-specific bioluminescence facilitates speciation in the deep sea. Mar Biol 161:1139-1148 
Desai S, Heffelfinger AK, Orcutt TM, et al (2008) The medaka novel immune-type receptor (NITR) gene clusters reveal an extraordinary degree of divergence in variable domains. BMC Evol Biol 8:177

Dirscherl H, McConnell SC, Yoder JA, de Jong JLO (2014) The MHC class I genes of zebrafish. Dev Comp Immunol 46:11-23

Dornburg A, Federman S, Lamb AD, et al (2017) Cradles and museums of Antarctic teleost biodiversity. Nat Ecol Evol 1:1379-1384

Dornburg A, Sidlauskas B, Santini F, et al (2011) The influence of an innovative locomotor strategy on the phenotypic diversification of triggerfish (family: Balistidae). Evolution 65:1912-1926

Dornburg A, Townsend JP, Friedman M, Near TJ (2014) Phylogenetic informativeness reconciles ray-finned fish molecular divergence times. BMC Evol Biol 14:169

Fabbri M, Mongiardino Koch N, Pritchard AC, et al (2017) The skull roof tracks the brain during the evolution and development of reptiles including birds. Nat Ecol Evol 1:1543-1550

Fernández R, Gabaldón T (2020) Gene gain and loss across the metazoan tree of life. Nat Ecol Evol 4:524-533

Ferraresso S, Kuhl H, Milan M, et al (2009) Identification and characterisation of a novel immune-type receptor (NITR) gene cluster in the European sea bass, Dicentrarchus labrax, reveals recurrent gene expansion and diversification by positive selection. Immunogenetics 61:773-788

Friedman M, Keck BP, Dornburg A, et al (2013) Molecular and fossil evidence place the origin of cichlid fishes long after Gondwanan rifting. Proc Biol Sci 280:20131733

Friedman ST, Martinez CM, Price SA, Wainwright PC (2019) The influence of size on body shape diversification across Indo $\square$ Pacific shore fishes*. Evolution 73:1873-1884

Gajdzik L, Aguilar-Medrano R, Frédérich B (2019) Diversification and functional evolution of reef fish feeding guilds. Ecol Lett 22:572-582

Gao F-X, Lu W-J, Wang Y, et al (2018) Differential expression and functional diversification of diverse immunoglobulin domain-containing protein (DICP) family in three gynogenetic clones of gibel carp. Dev Comp Immunol 84:396-407

Glasauer SMK, Neuhauss SCF (2014) Whole-genome duplication in teleost fishes and its evolutionary consequences. Mol Genet Genomics 289:1045-1060

Grande L (2010) An Empirical Synthetic Pattern Study of Gars (Lepisosteiformes) and Closely Related Species, Based Mostly on Skeletal Anatomy: The Resurrection of Holostei. Copeia 2010(2A):iii-871

Haire RN, Cannon JP, O'Driscoll ML, et al (2012) Genomic and functional characterization of the diverse immunoglobulin domain-containing protein (DICP) family. Genomics 99:282291

Hoang DT, Chernomor O, von Haeseler A, et al (2018) UFBoot2: Improving the Ultrafast 
Bootstrap Approximation. Mol Biol Evol 35:518-522

Holt C, Yandell M (2011) MAKER2: an annotation pipeline and genome-database management tool for second-generation genome projects. BMC Bioinformatics 12:491

Hughes LC, Ortí G, Huang Y, et al (2018) Comprehensive phylogeny of ray-finned fishes (Actinopterygii) based on transcriptomic and genomic data. Proc Natl Acad Sci U S A 115:6249-6254

Iglesias TL, Dornburg A, Warren DL, et al (2018) Eyes Wide Shut: the impact of dim-light vision on neural investment in marine teleosts. J Evol Biol 31:1082-1092

Inoue J, Sato Y, Sinclair R, et al (2015) Rapid genome reshaping by multiple-gene loss after whole-genome duplication in teleost fish suggested by mathematical modeling. Proc Natl Acad Sci U S A 112:14918-14923

Jones DT, Taylor WR, Thornton JM (1992) The rapid generation of mutation data matrices from protein sequences. Comput Appl Biosci 8:275-282

Kalyaanamoorthy S, Minh BQ, Wong TKF, et al (2017) ModelFinder: fast model selection for accurate phylogenetic estimates. Nature Methods 14:587-589

Kapustin Y, Souvorov A, Tatusova T, Lipman D (2008) Splign: algorithms for computing spliced alignments with identification of paralogs. Biol Direct 3:20

Kasahara M (1999) The chromosomal duplication model of the major histocompatibility complex. Immunol Rev 167:17-32

Kasahara M, Flajnik MF (2019) Origin and evolution of the specialized forms of proteasomes involved in antigen presentation. Immunogenetics 71:251-261

Katoh K, Standley DM (2014) MAFFT: iterative refinement and additional methods. Methods Mol Biol 1079:131-146

Langevin C, Aleksejeva E, Passoni G, et al (2013) The antiviral innate immune response in fish: evolution and conservation of the IFN system. J Mol Biol 425:4904-4920

Lefranc M-P, Giudicelli V, Duroux P, et al (2015) IMGT®, the international ImMunoGeneTics information system ${ }^{\circledR} 25$ years on. Nucleic Acids Res 43:D413-22

Letunic I, Bork P (2018) 20 years of the SMART protein domain annotation resource. Nucleic Acids Res 46:D493-D496

Litman GW, Hawke NA, Yoder JA (2001) Novel immune-type receptor genes. Immunol Rev $181: 250-259$

Litman GW, Yoder JA, Cannon JP, Haire RN (2003) Novel Immune-type Receptor Genes and the Origins of Adaptive and Innate Immune Recognition. Integr Comp Biol 43:331-337

Minh BQ, Nguyen MAT, von Haeseler A (2013) Ultrafast approximation for phylogenetic bootstrap. Mol Biol Evol 30:1188-1195

Montgomery BC, Cortes HD, Mewes-Ares J, et al (2011) Teleost IgSF immunoregulatory 
receptors. Dev Comp Immunol 35:1223-1237

Nakamura T, Yamada KD, Tomii K, Katoh K (2018) Parallelization of MAFFT for large-scale multiple sequence alignments. Bioinformatics 34:2490-2492

Nakatani M, Miya M, Mabuchi K, et al (2011) Evolutionary history of Otophysi (Teleostei), a major clade of the modern freshwater fishes: Pangaean origin and Mesozoic radiation. BMC Evol Biol 11:177

Near TJ, Dornburg A, Eytan RI, et al (2013) Phylogeny and tempo of diversification in the superradiation of spiny-rayed fishes. Proc Natl Acad Sci U S A 110:12738-12743

Near TJ, Dornburg A, Kuhn KL, et al (2012a) Ancient climate change, antifreeze, and the evolutionary diversification of Antarctic fishes. Proc Natl Acad Sci U S A 109:3434-3439

Near TJ, Eytan RI, Dornburg A, et al (2012b) Resolution of ray-finned fish phylogeny and timing of diversification. Proc Natl Acad Sci U S A 109:13698-13703

Near TJ, Kim D (2021) Phylogeny and time scale of diversification in the fossil-rich sunfishes and black basses (Teleostei: Percomorpha: Centrarchidae). Mol Phylogenet Evol 161:107156

Nei M, Rooney AP (2005) Concerted and birth-and-death evolution of multigene families. Annu Rev Genet 39:121-152

Nesbitt SJ (2003) Arizonasaurus and its implications for archosaur divergence. Proc Biol Sci 270 Suppl 2:S234-7

Nguyen L-T, Schmidt HA, von Haeseler A, Minh BQ (2015) IQ-TREE: a fast and effective stochastic algorithm for estimating maximum-likelihood phylogenies. Mol Biol Evol 32:268274

Pasquier J, Cabau C, Nguyen T, et al (2016) Gene evolution and gene expression after whole genome duplication in fish: the PhyloFish database. BMC Genomics 17:368

Pietretti D, Wiegertjes GF (2014) Ligand specificities of Toll-like receptors in fish: indications from infection studies. Dev Comp Immunol 43:205-222

Price SA, Schmitz L, Oufiero CE, et al (2014) Two waves of colonization straddling the K-Pg boundary formed the modern reef fish fauna. Proc Biol Sci 281:20140321

Prum RO, Berv JS, Dornburg A, et al (2015) A comprehensive phylogeny of birds (Aves) using targeted next-generation DNA sequencing. Nature 526:569-573

Quang LS, Gascuel O, Lartillot N (2008) Empirical profile mixture models for phylogenetic reconstruction. Bioinformatics 24:2317-2323

Rebl A, Goldammer T, Seyfert H-M (2010) Toll-like receptor signaling in bony fish. Vet Immunol Immunopathol 134:139-150

Rodríguez-Nunez I, Wcisel DJ, Litman GW, Yoder JA (2014) Multigene families of immunoglobulin domain-containing innate immune receptors in zebrafish: deciphering the differences. Dev Comp Immunol 46:24-34 
Rodriguez-Nunez I, Wcisel DJ, Litman RT, et al (2016) The identification of additional zebrafish DICP genes reveals haplotype variation and linkage to MHC class I genes.

Immunogenetics 68:295-312

Salzburger W (2018) Understanding explosive diversification through cichlid fish genomics. Nat Rev Genet 19:705-717

Seehausen $O$ (2006) African cichlid fish: a model system in adaptive radiation research. Proceedings of the Royal Society B: Biological Sciences 273:1987-1998

Shah RN, Rodriguez-Nunez I, Eason DD, et al (2012) Development and characterization of antinitr9 antibodies. Adv Hematol 2012:596925

Sibert E, Friedman M, Hull P, et al (2018) Two pulses of morphological diversification in Pacific pelagic fishes following the Cretaceous-Palaeogene mass extinction. Proceedings of the Royal Society B: Biological Sciences 285:20181194

Sievers F, Higgins DG (2018) Clustal Omega for making accurate alignments of many protein sequences. Protein Sci 27:135-145

Siqueira AC, Bellwood DR, Cowman PF (2019) Historical biogeography of herbivorous coral reef fishes: The formation of an Atlantic fauna. Journal of Biogeography

Smithwick FM, Stubbs TL (2018) Phanerozoic survivors: Actinopterygian evolution through the Permo-Triassic and Triassic-Jurassic mass extinction events. Evolution 72:348-362

Soubrier J, Steel M, Lee MSY, et al (2012) The influence of rate heterogeneity among sites on the time dependence of molecular rates. Mol Biol Evol 29:3345-3358

Strong SJ, Mueller MG, Litman RT, et al (1999) A novel multigene family encodes diversified variable regions. Proc. Natl. Acad. Sci. U. S. A. 96:15080-15085

Takezaki N (2018) Global Rate Variation in Bony Vertebrates. Genome Biol Evol 10:1803-1815

Thompson A, Hawkins M, Parey E, et al (2021) The genome of the bowfin (Amia calva) illuminates the developmental evolution of ray-finned fishes. Nature Genetics (accepted). https://doi.org/10.21203/rs.3.rs-92055/v1

Traver D, Yoder JA (2020) Chapter 19 - Immunology. In: Cartner SC, Eisen JS, Farmer SC, et al. (eds) The Zebrafish in Biomedical Research. Academic Press, pp 191-216

Tukwasibwe S, Nakimuli A, Traherne J, et al (2020) Variations in killer-cell immunoglobulin-like receptor and human leukocyte antigen genes and immunity to malaria. Cell Mol Immunol 17:799-806

Uhrberg M, Parham P, Wernet P (2002) Definition of gene content for nine common group B haplotypes of the Caucasoid population: KIR haplotypes contain between seven and eleven KIR genes. Immunogenetics 54:221-229

Vilches C, Parham P (2002) KIR: diverse, rapidly evolving receptors of innate and adaptive immunity. Annu Rev Immunol 20:217-251

Wang Y, Tang H, Debarry JD, et al (2012) MCScanX: a toolkit for detection and evolutionary 
analysis of gene synteny and collinearity. Nucleic Acids Res 40:e49

Wcisel DJ, Howard JT 3rd, Yoder JA, Dornburg A (2020) Transcriptome Ortholog Alignment Sequence Tools (TOAST) for phylogenomic dataset assembly. BMC Evol Biol 20:41

Wcisel DJ, Ota T, Litman GW, Yoder JA (2017) Spotted Gar and the Evolution of Innate Immune Receptors. J Exp Zool B Mol Dev Evol. https://doi.org/10.1002/jez.b.22738

Wcisel DJ, Yoder JA (2016) The confounding complexity of innate immune receptors within and between teleost species. Fish Shellfish Immunol 53:24-34

Wei S, Zhou J-M, Chen X, et al (2007) The zebrafish activating immune receptor Nitr9 signals via Dap12. Immunogenetics 59:813-821

Whelan S, Goldman N (2001) A general empirical model of protein evolution derived from multiple protein families using a maximum-likelihood approach. Mol Biol Evol 18:691-699

Wickham H (2011) ggplot2. Wiley Interdisciplinary Reviews: Computational Statistics 3:180-185

Williams AF, Barclay AN (1988) The immunoglobulin superfamily--domains for cell surface recognition. Annu Rev Immunol 6:381-405

Yamaguchi T, Dijkstra JM (2019) Major Histocompatibility Complex (MHC) Genes and Disease Resistance in Fish. Cells 8.: https://doi.org/10.3390/cells8040378

Yamanoue $\mathrm{Y}$, Miya M, Doi $\mathrm{H}$, et al (2011) Multiple invasions into freshwater by pufferfishes (teleostei: tetraodontidae): a mitogenomic perspective. PLoS One 6:e17410

Yang Z (1994) Maximum likelihood phylogenetic estimation from DNA sequences with variable rates over sites: approximate methods. J Mol Evol 39:306-314

Yoder JA (2009) Form, function and phylogenetics of NITRs in bony fish. Dev Comp Immunol 33:135-144

Yoder JA, Cannon JP, Litman RT, et al (2008) Evidence for a transposition event in a second NITR gene cluster in zebrafish. Immunogenetics 60:257-265

Yoder JA, Litman GW (2011) The phylogenetic origins of natural killer receptors and recognition: relationships, possibilities, and realities. Immunogenetics 63:123-141

Yoder JA, Litman RT, Mueller MG, et al (2004) Resolution of the novel immune-type receptor gene cluster in zebrafish. Proc Natl Acad Sci U S A 101:15706-15711

Yoder JA, Turner PM, Wright PD, et al (2010) Developmental and tissue-specific expression of NITRs. Immunogenetics 62:117-122 
Figure legends

Fig. 1. Bowfin DICPs are encoded within the MHC. a The main bowfin DICP gene cluster is encoded within the MHC on pseudochromosome Aca_scaf_14 (Thompson et al. 2021). The DICP gene cluster is flanked by clusters of MHC Class I Z lineage genes (mhc1zaa, mhc1zba and mhc1zca) and MHC Class I L lineages genes (mhc1laa, mhc1/ba and mhc1/ca). A single DICP pseudogene (dicp21p) is encoded on scaffold Aca_scaf_11 (not shown, see

Supplementary Table S1). b The spotted gar MHC and DICP cluster are currently fragmented in the reference genome leading to limited, but compelling, evidence for conserved synteny between bowfin and gar (e.g. prrt1, ddah2 and csnk2b). Each pentagon reflects a single gene with transcriptional orientation indicated. Gene sequence identifiers are shown above the genes (a-b) and DICP gene names are shown below the gene (b). c A detailed exon map represents the current knowledge of DICP genomic organization within the reference genome. Nucleotide position within Aca_scaf_14 is indicated on the left and right of each genomic region. $r=$ predicted exons with reversed transcriptional orientation.

Fig. 2. Conservation of the DICP D1 domain in bowfin. Protein sequence alignment of the D1 region of Bowfin DICPs compared with representative spotted gar and zebrafish sequences. Sequences are shaded by similarity with dashes indicating gaps in the alignment. Identical residues are shaded dark gray; structurally similar residues shaded light gray; and conserved cysteines shaded red. Key residues are numbered using the IMGT numbering system (Lefranc et al. 2015). Asterisks $\left(^{*}\right)$ indicate cysteines indicative of a DICP D1.

Fig. 3. Conservation of the DICP D2 domain in bowfin. Protein sequence alignment of the D2 region of Bowfin DICPs compared with representative spotted gar and zebrafish sequences. Sequences are shaded by similarity with dashes indicating gaps in the alignment. Identical 
residues are shaded dark gray; structurally similar residues shaded light gray; and conserved cysteines shaded red. Key residues are numbered using the IMGT numbering system (Lefranc et al. 2015). Asterisks $\left(^{*}\right)$ indicate cysteines indicative of a DICP D2.

Fig. 4. DICP diversity does not reflect holostean monophyly. Maximum likelihood phylogeny of DICP D1 and D2 domains inferred using IQ-TREE. Circles at nodes indicate bootstrap support values (BSS) with filled black circles black indicating BSS=100, gray circles indicating BSS values equal to or greater than 90 but less than 100, and white circles indicating BSS values greater than 70 but less than 90 . Lineages are indicated by the color coded arcs surrounding the tree and colored taxon labels (light blue = zebrafish [Danio rerio, Dare]; dark blue = carp [Cyprinus carpio, Cyca and Ctenopharyngodon idella, Ctid]; turquoise = coelacanth [Latimeria chalumnae, Lach]; gray = pufferfish [Tetraodon nigroviridis, Teni]; dark purple = tilapia [Oreochromis niloticus, Orni]; light purple = salmon [Salmo salar, Sasa]; orange = Holostei [Amia calva, Amca and Lepisosteus oculatus, Leoc]). For holosteans, spotted gar sequences are indicated in brown and bowfin sequences are indicated in orange. The following sequence identifiers are abbreviated in the figure: Leoc LG29:293175 = Leoc LG29:293175293459; Leoc JH591438 = Leoc JH591438:384055-384327; Leoc 00000000830 = Leoc ENSLOCG00000000830; Leoc LG29:151548 = Leoc LG29:151548-151823; Leoc 00000000745 = Leoc ENSLOCG00000000745; Leoc LG29:252003 = Leoc LG29:252003-252305; Leoc LG29:251128 = Leoc LG29:251128-251469; Leoc LG29:261282 = Leoc LG29:261282-261614; Lach JH130480.1 = Lach JH130480.1:43891-44139; Lach JH130632.1 = Lach JH130632.1:37775-37984; Ctid Cl01000243:00274762 = Ctid Cl01000243:0027476200275673; Ctid Cl01000243:00284609 = Ctid Cl01000243:00284609-00301594; and Cyca LG38:21616820 = Cyca LG38:21616820-21618149. Scale bar indicates substitutions per million years. 
Fig. 5. Predicted DICP protein architecture. Select DICP protein structures reflect sequences identified from a the bowfin reference genome, b RNA-seq from a single bowfin (0039) and c the PhyloFish database. Protein domains include: Ig D1 and D2 domains (orange), transmembrane domains (TM), cytoplasmic ITIM and ITIM-like (itim) sequences. The presence of a charged arginine within a TM indicates a potential activating receptor and is indicated by a green circle. Sequences that are predicted to be truncated at the 5' and/or 3' are indicated by asterisks $\left(^{*}\right)$. Shading of Dicp20 and "DICP3.3.1.1" indicate that they may reflect the same gene (see Supplementary Note 2 and Fig. S4). Note that PhyloFish transcript names do not correspond to the genome-based DICP gene nomenclature. Shading of 1382_c24_g1_i1 (from bowfin 0039) and LOC100333982.2.2 (from PhyloFish) indicate that they likely reflect the same gene product and may represent Dicp1 (see Supplementary Note 2 and Fig. S9).

Fig. 6. Bowfin NITRs are encoded on scaffold Aca_scaf_8. The syntenic relationship between the NITR gene clusters on spotted gar linkage group 14 (a) and bowfin pseudochromosome Aca_scaf_8 (b) is indicated. A number of genes flanking the NITR clusters (e.g. runx 1, donson, and a number of olfactory receptors) are conserved in both holostean species. Each pentagon reflects a single gene with transcriptional orientation indicated. Gene sequence identifiers are shown above the genes (ENSEMBL for gar and AMCG for bowfin) with common gene symbols below. (c) A detailed exon map represents the current knowledge of NITR genomic organization within the reference genome. Nucleotide position within Aca_scaf_8 is indicated on the left and right of each genomic region.

\section{Fig. 7. Conservation of the NITR I domain in bowfin demonstrates I-J motifs in both}

species of holosteans. Protein sequence alignment of the I region of bowfin NITRs compared with representative spotted gar and zebrafish sequences with the conserved $\mathrm{J}$ domain indicated for all species. Sequences are shaded by similarity with dashes indicating gaps in the 
alignment. Identical residues are shaded dark gray; structurally similar residues shaded light gray; and conserved cysteines shaded red. Key residues are numbered using the IMGT numbering system (Lefranc et al. 2015). Asterisks ( ${ }^{*}$ ) indicate cysteines indicative of a NITR I domain.

Fig. 8. Conservation of the NITR V domain in bowfin demonstrates V-J motifs in both species of holosteans. Protein sequence alignment of the $\mathrm{V}$ region of bowfin NITRs compared with representative spotted gar and zebrafish sequences with the conserved $\mathrm{J}$ domain indicated for all species. Sequences are shaded by similarity with dashes indicating gaps in the alignment. Identical residues are shaded dark gray; structurally similar residues shaded light gray; and conserved cysteines shaded red. An internal stop codon in Nitr9p-V is represented by an asterisk and a frame shift in Nitr30-V is represented by (fs). Key residues are numbered using the IMGT numbering system (Lefranc et al. 2015).

Fig. 9. NITR I domain diversification mirrors lineage-specific gene expansions observed in teleosts, but with slower molecular rates. Maximum likelihood phylogeny of NITR I domains inferred using IQ-TREE. Circles at nodes indicate bootstrap support values (BSS) with filled black circles black indicating $B S S=100$, gray circles indicating BSS values greater than 90 but less than 100, and white circles indicating BSS values greater than 70 but less than 90 . Lineages are indicated by the color coded arcs surrounding the tree and colored taxon labels (light blue = zebrafish [Danio rerio, Dare]; dark blue = medaka [Oryzias latipes, Orla]; purple = pufferfish [Sphoeroides nephelus, Spne]; orange = Holostei [Amia calva, Amca and Lepisosteus oculatus, Leoc]:). For holosteans, spotted gar sequences are indicated in brown and bowfin sequences are indicated in orange. Gar ENSEMBL sequence identifiers are abbreviated by removing "ENSLOCG" from the identifier in the figure (e.g. "Leoc ENSLOCG00000008554" is 
abbreviated "Leoc 00000008554"). Scale bar indicates substitutions per million years and asterisks $\left(^{* * *}\right)$ indicates branch length scaled by $50 \%$ for visualization.

Fig. 10. Holostean NITR V domain diversification is slower than that of teleosts. Maximum likelihood phylogeny of NITR V domains inferred using IQ-TREE. Circles at nodes indicate bootstrap support values (BSS) with filled black circles black indicating BSS=100, gray circles indicating BSS values greater than 90 but less than 100, and white circles indicating BSS values greater than 70 but less than 90 . Lineages are indicated by the color coded arcs surrounding the tree and colored taxon labels (light blue = zebrafish [Danio rerio, Dare]; dark blue = medaka [Oryzias latipes, Orla]; purple = pufferfish [Sphoeroides nephelus, Spne]; orange = Holostei [Amia calva, Amca and Lepisosteus oculatus, Leoc]). For holosteans, spotted gar sequences are indicated in brown and bowfin sequences are indicated in orange. Gar ENSEMBL sequence identifiers are abbreviated by removing "ENSLOCG" from the identifier in the figure (e.g. "Leoc ENSLOCG00000008554" is abbreviated "Leoc 00000008554". Scale bar indicates substitutions per million years and asterisks $\left(^{* * *}\right)$ indicates branch length scaled by $50 \%$ for visualization.

Fig. 11. Predicted NITR protein architecture. Select NITR protein structures reflect sequences identified from $\mathbf{a}$ the bowfin reference genome and from $\mathbf{b}$ RNA-seq from a single bowfin (0039) and c from the PhyloFish database. Protein domains include: Ig V and I domains (blue), transmembrane domains (TM), cytoplasmic ITIM and ITIM-like (itim) sequences. The presence of a charged arginine within a TM indicates a potential activating receptor and is indicated by a green circle. Sequences that are expected to be truncated at the 5' and/or 3' are indicated by asterisks $\left(^{*}\right)$. Nitr27 encodes a truncated I domain which is shown as a compressed Ig domain. Shading of Nitr16 with 6505_c0_g1_i12, Nitr17 with 6505_c0_g1_i9, and Nitr21 with 6505_c0_g1_i4 indicate that they may reflect the same gene (see Supplementary Note 3 and 
bioRxiv preprint doi: https://doi.org/10.1101/2021.06.11.448072; this version posted June 11, 2021. The copyright holder for this preprint (which was not certified by peer review) is the author/funder, who has granted bioRxiv a license to display the preprint in perpetuity. It is made available under aCC-BY 4.0 International license.

Figs. S13-S15). Note that PhyloFish transcript names do not correspond to the genome-based NITR gene nomenclature. 
bioRxiv preprint doi: https://doi.org/10.1101/2021.06.11.448072; this version posted June 11, 2021. The copyright holder for this preprint (which was not certified by peer review) is the author/funder, who has granted bioRxiv a license to display the preprint in perpetuity. It is made available under aCC-BY 4.0 International license.

a

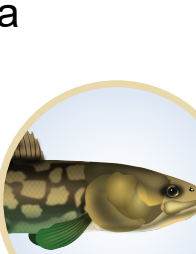

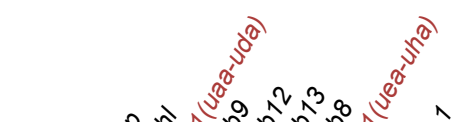

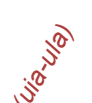

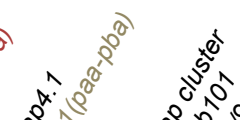

$i^{\infty}$

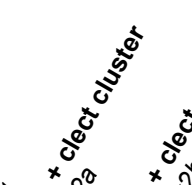

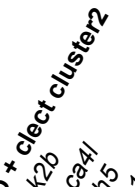

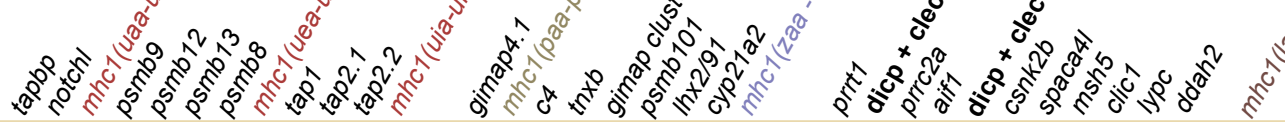

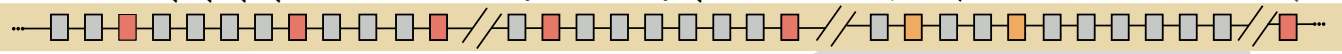

Scaffold 14

Expanded in b

\section{Bowfin}

b Spotted Gar LG29 $19 \mathrm{kbp}$ JH591438.1

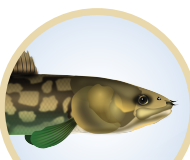
$5, \frac{10}{60}$ 65

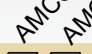

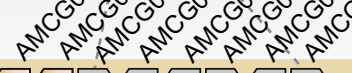

Bowfin 1339686

C
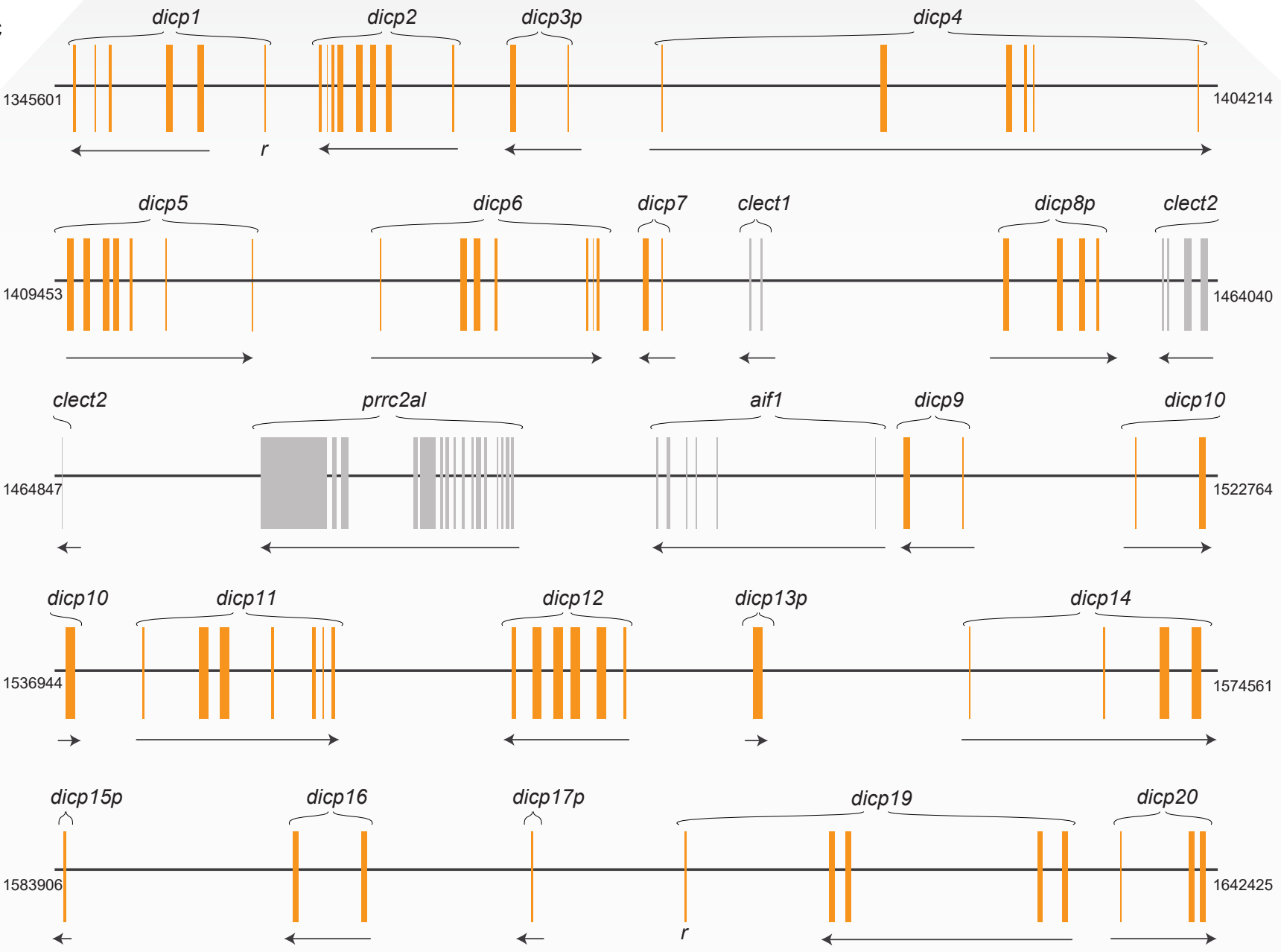

$\square$ DICP forward $\square$ Uncharacterized gene (forward) $\square$ Characterized gene (forward)
$\square$ DICP reverse $\square$ Uncharacterized gene (reverse) $\square$ Characterized gene (reverse)

Exon (DICP) |Exon (non-DICP) 
bioRxiv preprint doi: https://doi.org/10.1101/2021.06.11.448072; this version posted June 11, 2021. The copyright holder for this preprint (which was not certified by peer review) is the author/funder, who has granted bioRxiv a license to display the preprint in perpetuity. It is made available under aCC-BY 4.0 International license.

\section{Bowfin}

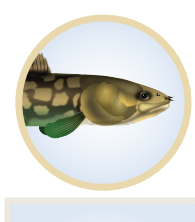

Identical residues

Structurally similar

Conserved

cysteines

\section{Spotted Gar}

JH591438:384055-384327-D1 LG29:293175-293459-D1 LG29:252003-252305-D1

LG29:151548-151823-D1 ENSLOCG00000000830-D1 ENSLOCG00000000745-D1

\section{Zebrafish}

Dicp1.3-4(AFC88163.1)-D1 Dicp2.1(ANH22376.1)-D1 Dicp3.1(ANH22382.1)-D1

Dicp2-D1b

Dicp4-D1

Dicp5-D1a

Dicp6-D1

Dicp7-D1

Dicp10-D1

Dicp11-D1

Dicp12-D1a

Dicp13p-D1

Dicp14-D1

Dicp16-D1

Dicp19-D1b

Dicp20-D1

Dicp21p-D1b
iั ช
* 5

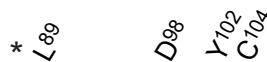

Dicp1-D1

ESYTTTLSDELFSTVGRLLLLSCVAPV--SLGPGETLRWTYRQSRTSOAVVLYSLRSLTETPLKGTVPHSGRAVMSANSSLLIHNVQTGDAGLYCCQRDKD--SGPKKTHRTFAI VLGIKSSGDTLYSSVGGSAILPCVGVT---HQHCPSTTWMLSRKFR-PDTEVVKLGKVT-----DVE-RAGRLSVGSDCSLHIERLKSPDAGVYTCSHRNT--PGT------SVTI TTELTDGIQQVYRVVGSSVTLPCAINVTQTLGQGEKLEWFLRTWDDPIGHTLFSLSSDWKVSPINPTVV-PGVKMAANSSLVLPALSAQHSGIYLCSLYSG--SSVKKELWRL---------ELFSTVGRLLLLSCVAPV--SLGPQETLRWTYRQSRTSQAVVLYSLRSLTETPLKGTVPHSGRAVMSANSSLLIHNVQTGDAGLYCCQRDKD--SGPKKTHRTFAI SNAAPLTAVVLYSTLGASVTVPCDGLT---EYDNSYIVWVFAHSSD-TSVELSRGGMIT---DTDPD-RAGRLRLGSNRYLHIDRLRTRDTGEYNCHQHVN--GHFYESGSTVI --YTTTLSDELFSTVGRLLLLPCVDPV--SLGPGERLRWTYRQPVSSAPVTLYELLSQSITPLRGKDTHSGRAVMSVNSSLLIHNVQTRDAGLYRCERHKD--LKYQKTHRRFAL STAAPLTDVTVFSTVGGSAALRCETVI---YTDCSSTRWLFNRRSQ-AAVELVNLGKVK---NNNLE-RAGRLSVGSDCSLHIDRLHTQDTGVYTCRQFIN--EQKQGGDNTVYL NTAAPITGVAVYSSVGGSATLPCEGEI---NTDCSSSAWFFKETHM-----LD---------TNG-KPGKLSVGSNCSLQIYNLSTEDAGNYSCHQQIN--GQHNNKVNL--STAAPLTGVAVFSTVGGIADLHCKTVI---YTNCSSTTWNFNSGSQ-TTVELVGLGKVK---NNNPE-RAGRLSLGSNCSLHIDRLHTQDTGLYYCQQFIN--GQKQGVDNTVYL STAASLTGVAVFSTVGGIADLHCKTVI---YTNCSSTVWNFNSGSQ-TTVELVGLGKVK---NNNPE-RAGRLSLGSNCSLHIDRLHTQDTGLYYCQQFIN--GKKQGVDYTVYI NTAAPLTGVAVYSTVGGSATLPCEGVI---NTDCSSTTWLFIQKSQ-LAVELVELGKIR---NYSPV-RARRQSVGSDCSLYIDRLHTKDTGLYYCQQFIN--GQKQGGDYSVYI ----_---_----ASVTVPCDGLT---EYHNSYISWVFNHRSE-TTVELSRGGMIT---DTDPD-RAGRLRLGSNSSLHIDRLRTRDTGQYNCHQYVN--GKYYTSGLTVTI TTKLSDFIREVYIRLGDFLOLPCLESV--HLGPGEILOWLVNKADT INYETLYTLSEDGOI-TTAMEVNPERLEMTVSSSLLIRSVOAODSGVYLCCFNEE--T------HEVYYI -------VAVYSTVGGSATLPCEGET---SGICSAVYWFFNKEIH--GVELVADGTIT---ARDPD-RGKSLSVGSDCSLHIARLHTQDTGPYICRPYFN--GKD----YPVSL STAAPLTGVAVFSTVGGSAALRCGTVI---YTNCSSTTWNFNSGSQ-TTVELVGLGKVN---NDSPE-RAGRLSVGSDCSLHIDRLHTQDTGHYYCQQFIN--GQKQGGDYRVYL ------VAVYSTVGGSATLPCEGAT---SGICSAVDWLFIKAPG-ELVHLVNHGRVT---ATDPE-RAGRLSVASDCSLHIDRLHTQDTGRYTCLPYFN--GRD----YL---------LSLYSSQGGEVTVSCEGLR---KYENDSIAWSYSHGIG-PPIELSRGMNIT---ATDPG-RAGRLRVLSDNSLHIDGLGPRDIGRYTCQQLIN--GRLNRSGSPVRL AIYTTKLTDEVYSTVGGLLLLPCVDPV--SLGRGETLRWTYRQPASSAPVTLYGLTSQSETPLAGKGVENQRAVMLANSSLLIHSVQTGDAGLYRCEENKT--QEML--------STAAPLTGVAVYSTVGGSATLPCEGAT---SGICSSIYWVFHKDDA-E---LVGGGRVT---ASDPE-RAGRLSVKSDCSLHIDRLHTQDTGHYYCRPHFN--GDD----YLVNL ---TCHFPEEVYSTVGGFLLLPCVDPV--SLGQGETLQWTYRQSHTSWAVVLYSLLTQTETPLRGNDTHSWRAVMSVNSSLIIHNVQTGDTGLYRCEGWTD--SGHTEIHRRFSI

---------FFSTVGGSVTLPCRGVI---RTDCSTTTWFFSSRPQRAAVELVALGRIR---DHKP----GRVRLGSDCSLHVHTLSTQDTGLYSCQQFVN--DQQQGQDSPV----------VFSTVGESVTLPCRGVI---RTGCSTTTWLFNSRSQSATVELVNVGKIR---DQEP----GRVSLGSDCSLHVHALSTQDTGLYTCOQFVK--GQKOGEDSRVYI ---------VYSTVGGSVGLPCENLK---EMNRSSIVWVFSQNPG-APIFLSKDKTIT---VRDPE-RAGRLRVGADWSLHIRSLWPQDSGLYTCVQYVS--GEYHRSGTTATL --------LFFSEGANVSLPCDGDR-----SCDSVSWKYNSRSG-PETLLIEKGQVV---TTQTD-RAGRLTVLSNCSLHIHNLKKEDTGQYTCGLHST--RRK------TVSI ---------VFSTVGGSVTLPCRGVN---RKDCSTTTWVFSSRSQRAAVELVNLGKIR---DQKP----GRVSLGSDCSLHVHTLSTQDTGLYTCQQFVY--DQQQGEDSPVSI ----------SEGGNVSLPCDGVS-----SCDSVSWKYNTGSG-PETLLIENGQDV---TTQTD-RAGRLTVLSDCSLHIHNLKKEDAGQYTCGPHST--RRK-----TISL

-------DIDVFSRSGETVHLPCNNTV--QHCRPSETTWTYGRYRQTTADELICFGRKK---A--KPEKHERLNLGSDCSLIISRVTTEDAGLYICQQWSGNQKQGNDSVVFLHV --ASGQKI IHVFSSDAENATLPCYNAS----ADCTSTTWAYYSKRGSPGIELFSNGK----------IHDRLSLGSDCSLNIYKTTTKDLGVYTCWLGVK--DTQK-TFGNVYI --TSGAEDI-LFFRSGENVSLPCNNAL----SGCTSTTWNYN--RGSNTIELVGVGKLN---N--ID-RRERLSVGSDCSLNIMNATKEDYGSYSCRQYVN--EQQQENDARVYL 
bioRxiv preprint doi: https://doi.org/10.1101/2021.06.11.448072; this version posted June 11, 2021. The copyright holder for this preprint (which was not certified by peer review) is the author/funder, who has granted bioRxiv a license to display the preprint in perpetuity. It is made available under aCC-BY 4.0 International license.

\section{Bowfin}

Identical residues

Structurally similar

residues

Conserved

cysteines

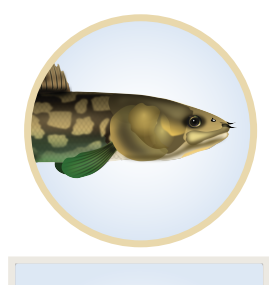

$0^{\circ} \quad 0^{3}$ *

$s^{x}$
* $\stackrel{\infty}{v}$

Dicp1-D2

Dicp2-D2a

Dicp2-D2b

Dicp4-D2

Dicp5-D2a

Dicp5-D2b

Dicp6-D2

Dicp10-D2

Dicp11-D2

Dicp12-D2a

Dicp12-D2b

Dicp14-D2

Dicp16-D2

Dicp19-D2a

Dicp19-D2b

Dicp20-D2

Dicp21p-D2a

Dicp21p-D2b

\section{Spotted Gar}

LG29:251128-251469-D2

LG29:261282-261614-D2

ENSLOCG00000000830-D2

ENSLOCG00000000745-D2

\section{Zebrafish}

Dicp1.3-4(AFC88163.1)-D2 Dicp2.1(ANH22376.1)-D2 Dicp3.1(ANH22382.1)-D2
LSISVSSSSSACLRAGDRLTLKCGLDCGGGAGSCSETP---QGLTLSWRDESGVPPKDERDRYSITE-LRGVHSQLSVTLRQSDHNKSWTCVLTERGEMKTS HLLNITVSLQTDLKSGTEIELHCFISTSSAIEPCNPPP---KGVRVGWVNGRGDALQG--SRYTVRN-ESVCHSVLTLTLQPSDHNTQWRCDLTQEGSQRVT HIVEVSSDPTGGIQKGSGINLTCSLTCEDV---CDK------NTELTWRDSAGCSLQGGPAERVNNT---LSSWLLVPELQS--SERIW-CSVVREGLERVE NTLSVSSNLSEEAQNGSAVTLTCSLTCGFD---CEE------NTELIWRDSTGNSLQGGTSERNKST---ISS-QLVLQPQS--SERIR-CSVEREGLERVS FLLSISASPSEGLRAGDRI TLSCVLDCGGMVGNCSET----QGLTLSWRDESGF PLKDERDRYSITE-LRGVHSHLSVTLRQSDHNKSRTCVLTERGEMKTS --LSVNSNPIADVHKGSAVSLTCSLTCGFD---CVE------NTELTWKNSTGNSLQGGASEHNKST---ISS-QLVLQPQS--SERIW-CSVEREGLERVS ALL I IEVPPETELKAGSTVTLRCLLHTGHGPVVCSHPPYTSADVRVSWVSETGAELQG--DTYQIST-DHPCLSTLTVRLQT SDHNTQWRCDLTEGGAVRVS ALL I IDVPPETELKAGSTVTLRCLLHTGHGPGDCSHPPYTSADVRLSWVSETGAELQG--DTYF--T-ERPCLSTLTVRLQT SDHNTQWRCDLTEGGAVRVS VLLIIDVPPETELKAGSTVTLRCFLHTGHSPGVCSH-PYTSADVRLSWVSETGAELQG--DTYQIST-DQPCLSTLTVRLQTSDHNTQWRCDLTEGGAVRVS FLLSITASPSENLKSGDRITLRCGLDCGGGAGSCSEAP---QGLTLTWRDESGAPLKDRRDRYEIKT-LA-NRSHLSVSLQRSDHYRLWVCALAEGGRVETC NTIWVSSDHTGEVKRGSNI TLTCTLTCGRIYGN--------ISNTLVWRDSTGHSLQGGTTEQMNNK---FISRLLVPELQS--SERIW-CSVVREGLERVE ALLIIDVPPETELKAGSTVTLRCLLHTGHGPGVCSHPPYTSADVRVSWVSETGAELQG--DTYQIST-DHPCLSTLTVRLQT SDHNTQWRCDLTEGGAVRVS NLALLSVPPETELKAGSIVTLRCFLDTEHGPGVCSH-PYTSADVRLSWVSETGAELQG--DTYQIST-DQPCLSTLTVRLQT SDHNTQWRCDLTEGGAVRVS GLLYITTSPSENLKVNDTLTLTCTVSVEGSFP-----P---KI PTLDWKI------KRSTGRIIMTG-VP-GRINLSVKLHRSDHGRNWVCDLSEDGKIFS LSVSSEQTGEVQKGNGSAVTLACSLTCGSG---CVE------DTELIWKNSTGHSLQGSASECNKST---ICS-QLVLQPQS--SERIR-CSVEREGLERVS ALLSVDVPPETELKAGSTVTLRCLLHTGHGPGDCSH-PYTSADVRLSWVSETGAELQG--DTYQIST-DHPCLSTLTVRLQT SDHNTQWRCDLTEGGAVRVS ----VMYSPHEDLRAGDRLTVLCGLVCGGDPGSCPVD----QGLTLSWRDESGVTLKEKRVRNENTG-FSGELSLLSVIVRQSDQNKSWTCVLTVRDEMKTS --FPVSSNLSGEAQKGSAVTLTCSLTCGFD---CVE------NTELTWRNSTGNSVQGGTSEHNNSI---ISS-QLVLQTQS--SEKIR-CSVEREGLERVS

ALSSVTASPSGNLRTGSMLTLRCGLDCGAGLGSCLETP---EGLTMSWWRDPDLVRKVEMGRSQIRD-FR-TYSQLSVTLQRSDHNKNWVCALLKGTELKTY ALSSVTASPSGNLRTGSVLTLRCGLDCGAGLGSCSRVP---EGLTVSWRRDQDLVGKVDTGRSQIRD-FR-TYSQLSVTLQRSDHNKNWVCVLAKGTELKTY ------SPGAELRTGSTVTLHCLLDTNWSPEHCPSPL---HSYTVIWVTETGAELQG--DRYQISS--SPCSSYLTVRLQPSDHSRQWRCDVTQDRAVTFT -------SVD PSLTGVNLSLYCRLYPDVDSAECNK----TKNLRLTWVDEQGAELKN--QRFKIRG-ASPCESVLTMKLRDSDRDQAWRCDLREEDELKAS

------SSSSDIGPGLSLTLSCQLYSDSGF-SC-DGLFSSEDLHLSWVNEAGVDLNTD-SRYQISS--TGCIISLSTTLISEDEDKQWRCGVYQRNQLKTS ----SPSSSQTQIKPGRSVTLFCQLYFCYEH-SC-ETLLSSEGLQLIWVNESGVNLQTD-SRFQILSSVDHCSISLTKTLLDEDDNTEWRCQITKGSEVKTS ----SSSLSQTEMRAGRSVTLKCKLEY-YGV-SC-DTLFRTEGYQLVWVNQAERNLATD-SRYKIFSS-SPCMISLTTTLLNEDHNKEWRCQLTQNNQLKTS 
bioRxiv preprint doi: https://doi.org/10.1101/2021.06.11.448072; this version posted June 11, 2021. The copyright holder for this preprint (which was not certified by peer review) is the author/funder, who has granted bioRxiv a license to display the preprint in perpetuity. It is made available under aCC-BY 4.0 International license.

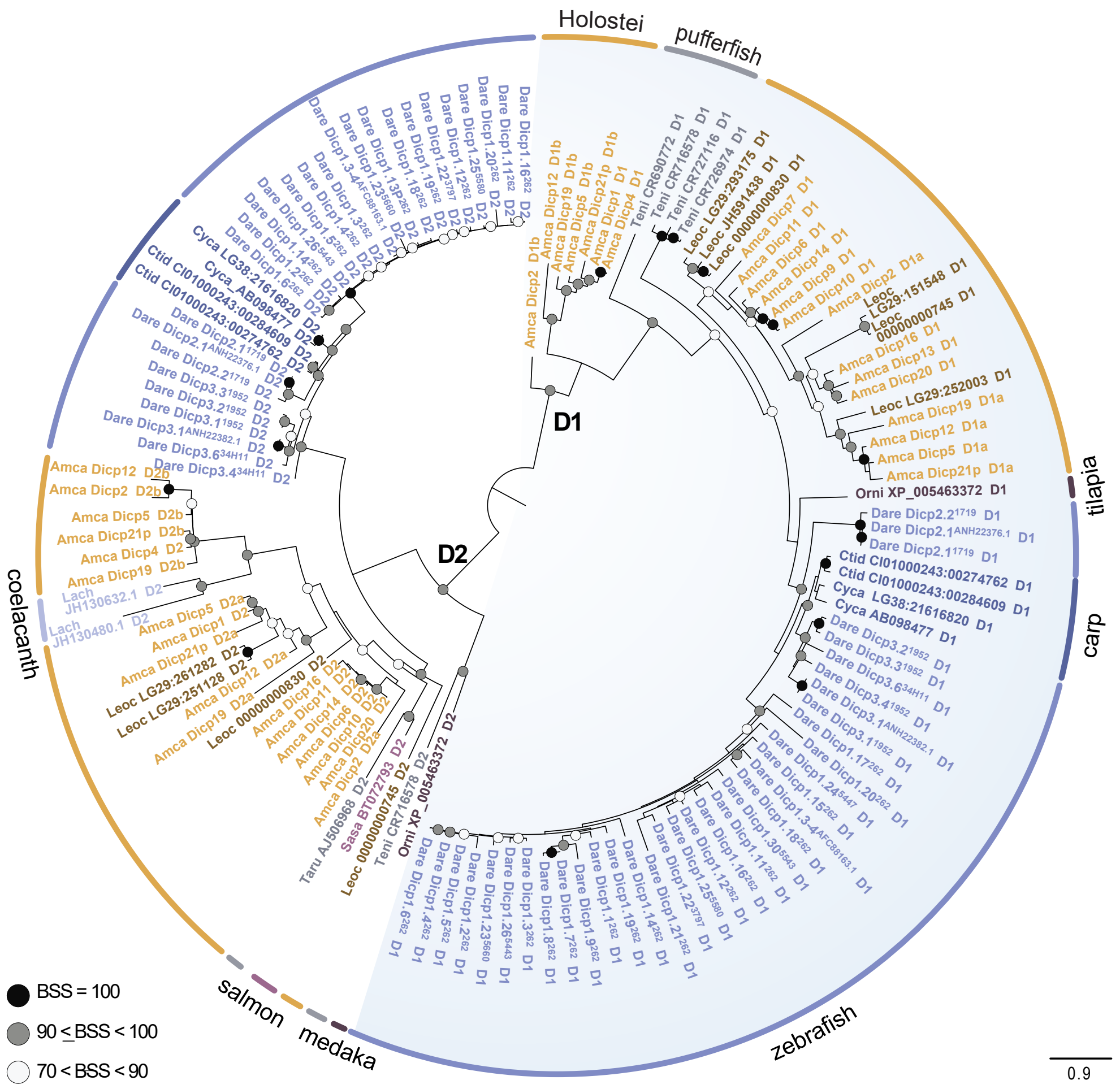


a

Genome Prediction

(Dict Dicp4 Dicp5 Dicp6 Dicp10 Dicp11 Dicp12 Dicp14 Dicp16 Dicp19 Dicp20



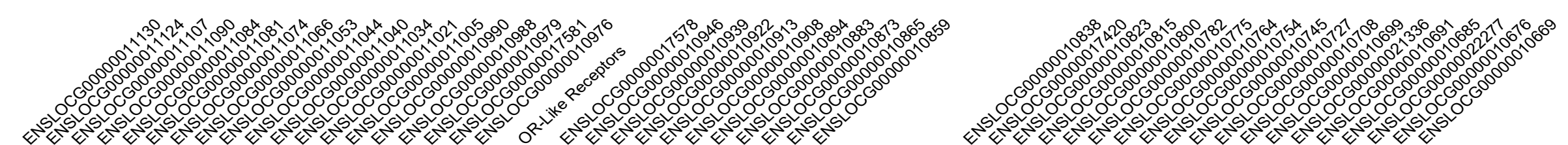
口卄1
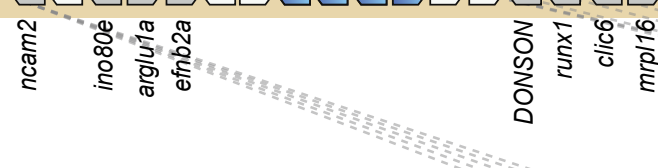

Spotted Gar

OR-Like

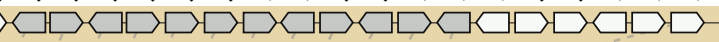

b
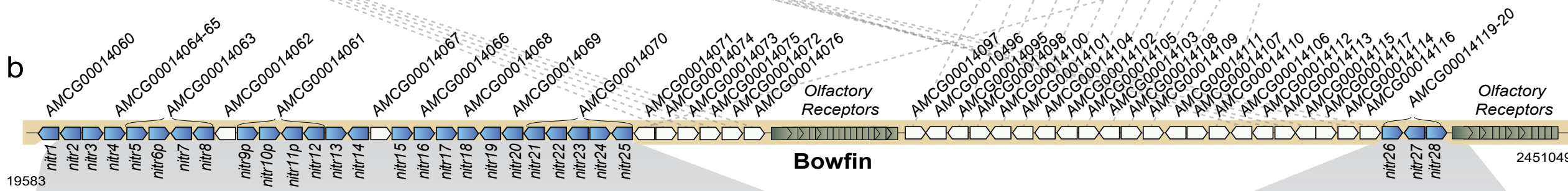

C

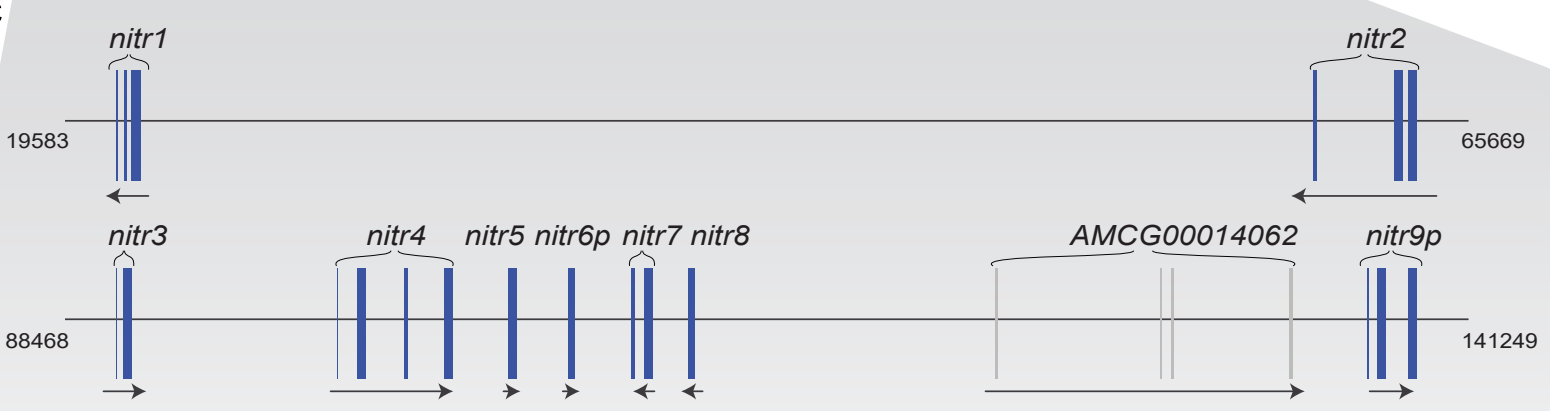

nitr10p nitr11p nitr12

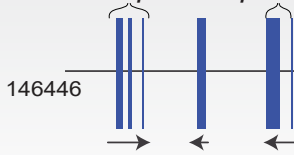

nitr15

217556

 nitr13 nitr14

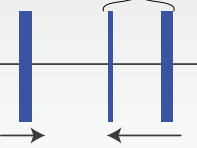

nitr16
AMCG00014067

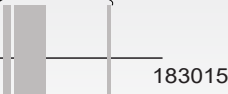

nitr18

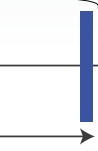

nitr21 nitr22 nitr23 nitr24

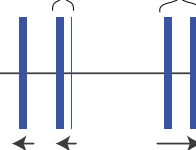

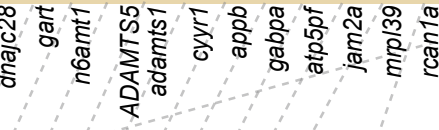
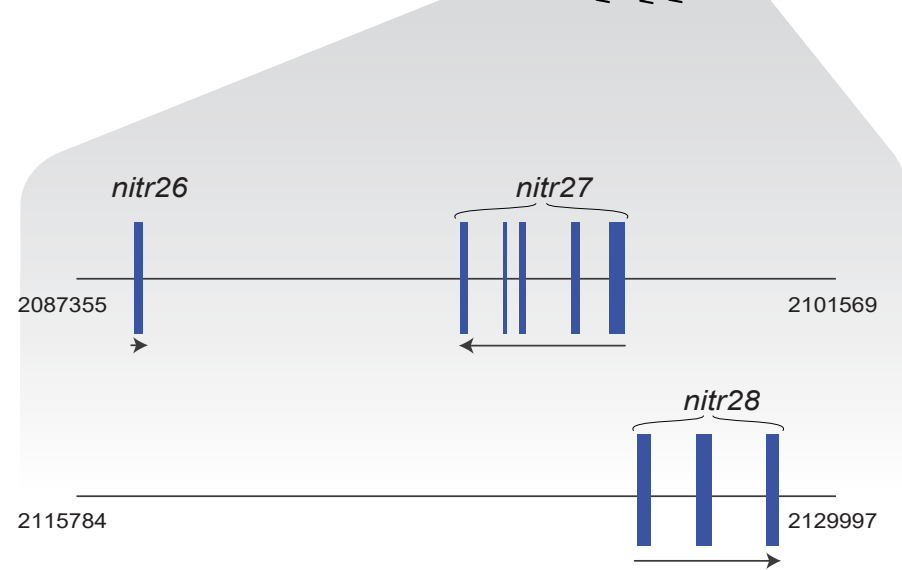

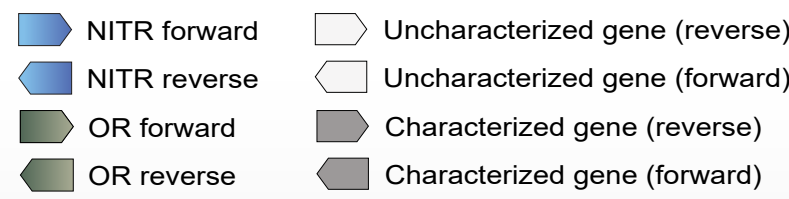

OR reverse
Syntenic gene

Exon (NITR) Exon (non-NITR) 
bioRxiv preprint doi: https://doi.org/10.1101/2021.06.11.448072; this version posted June 11, 2021. The copyright holder for this preprint (which was not certified by peer review) is the author/funder, who has granted bioRxiv a license to display the preprint in perpetuity. It is made available under aCC-BY 4.0 International license.

Bowfin

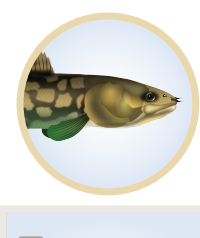

Identical residues

Structurally similar residues

Conserved cysteines

Spotted Gar

NITR1.1.4-I

ENSLOCG00000008542-I

ENSLOCG00000010883-I

ENSLOCG00000010922-I

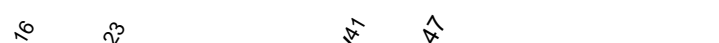

$\operatorname{sic}_{2}^{50}$

$\mathrm{J}$ domain

Nitr1-I SRTIVQWPVSVPVQP-GDSVTLQCTIHTE---TCAGEHSVHWFRHGSG--EALPGLIYTHGN---RSDPCESSSEPGLPAQGCVYELPKRNLHSSDAGTYYCAVATCGQILFGNGTRLDI Nitr2-I -----PPVSVPVQP-RDNVTLQCVTDYY---TCKGEHSVYWFRHRSG--ESLSGLI-THKN---QIDQCERSSELQFSTEYCVCSLTKTNLSSSDAGTYYCAVATSGEILFGNGTRLDI Nitr9p-I NRTIVQQPASFSVQP-GDSVTLQCTIHTE---TCAGEHSVHWFRHGSG--EALPGLIYTHGN---RSDPCESSSEPGLPAQGCFYELPKRNLRSSDAGTYYCAVATCGQILFGNGTRLDI Nitr11p-I RLRVRQQESGAAAGVCPRPVRRQCD-------SAVYNTHWFRHGSG--EALPGLIYTHGN---RSDPCESSSEPGLPAQGCVYELPKRNLRSSDAGTYYCAVATCGQILFGNGTRLDI Nitr14-I SRRVEQQPASVPVQP-GDSVTLQCTIHTE---TCAGEHSVHWFRHGSG--EALPGLIYTHGN---RSDPCESSSEPGLPAQGCVYELPKRNLRSSDAGTYYCAVATCGQILFGNGTRLDI Nitr16-I SRRVEQQPASVPVQS-GDSVTLQCTIYTE---PCAGEHSVHWFRHGSG--EALPGLIYTHGN---RSDPCESSSEPGLPAOGCVYELPKRNLCSSDAGTYYCAVATCGQILFGNGTRMDI Nitr18-I NRTVEQQPASVFVQP-GDSVTLQCTIHTE---TCAGEHSVHWFRHGSG--EALPGLIYTHGN---RSDPCESSSEPGLPAQGCVYEIPKRNLRSSDAGTYYCAVSTCGQILFGNGTRIDI Nitr20-I IRRVEORPASVLVOP-GDSVTLOCTIHTE---TCAGEHSVHWFRHGSG--EALPGLIYTHGN---RSDLCESSSEPGLPAOSCVYELPKRNLRSSDAGTYYCAVATCGOILFGNGTRLDI Nitr21-I SRRVEQQPASVPVQP-GDSVTLQCTIHTE---TCAGEHSVHWFRHGSG--EALPGLIYTHGN---RSDPCESSSEPGLPAQGCVYELPKRNLRSSDAGTYYCAVATCGQILFGNGTRLEF Nitr24-I SRRVEQQPASVPVQP-GDSVTLQCTIHTE---TCAGEHSVHWFRHGSG--EALPGLIYTHGN---RSDPFESSSEPGLPAQGCVYELPKRNLRSSDAGTYYCAVATCGQILFGNGTRLEF Nitr25-I ----VQQPASVPVQP-GDSVTLQCTIHTE---TCAGEHSVHWFRHGSG--EALPGLIYTHGN---RSDPCESSSEPGLPAQGCVYELPKRNLRSSDAGTYYCAVATCGQILFGNGTRLDI Nitr26-I ----------------KSLTLQCTIHTE---TCAGEHSVHWFRHGSG--EALPGLIYTHGN---RSDPCESSSEPGLPAQGCIYEL---------------------------------Nitr28-I SRRVEQQPASVPVQP-GDSVTLQCTIHTE---TCAGEHSVHWFRHGSG--EALPGLIYTHGN---RSDPCESSSEPGLPAQGCVYELPKRNLRSSDAGTYYCAVATCGQILFGNGARLHI Nitr29-I IRRVEQQPASVPVQP-GDSVTLQCTIHTE---TCAGEHSVHWFRHGSG--EALPGLIYTHGN---RSDPCESSSEPGLPAQGCVYELPKRNLCSSDAGTYYCAVATCGQILFGNGTRLDI Nitr30p-I IRRVEQQPASVPVQP-GDSVTLQCTIHTE---TCAGEHSVHWFRHGSG--EALPGLIYTHGN---RSDLCESSSEPGLPAQGCVYELPKRNLRSSDAGTYYCAVATCGQILFGNGTRLDI Nitr31-I SRRVEQOPASVPVQP-GDSVTLQCTIHTE---TCAGEHSVHWFRHGSG--EALPGLIYTHGN---RSDPCESSSEPGLPAQGCVYELPKRNLRSSDAGTYYCAVATCGQILFGNGTRLEF Nitr32-I SRRVEQQPASVPIQP-GDSVTLQCTIHTE---TCAGEHSVHWFRHGSG--EALPGLIYTHGN---RSDPCESSSEPGLPAQGCVYELPKRNLRSSDAGTYYCAVAKCGQILFGNGTRLDI Nitr33-I SRSVVQQLASVPVQP-GDSVTLQCTIHTE---TCAGEHSVHWFRHGSG--EALPGLIYTHGN---RSDPCESSSEPGLPAQGCVYELPKRNLRSSDAGTYYCAVATCGQILFGNGTGVCR Nitr34-I SRRVEQQPASVPVQP-GDSVTLQCTIHTE---TCAGEHSVHWFRHGSG--EALPGLIYTHGN---RSDPCESSSEPGLPAQGCVYELPKRNLRSSDAGTYYCAVATCGPILFGNGTRLDI

Zebrafish

Nitr1a-I RNTNLHQSLIETVDP-GDAVNLQCSIFTE---SCAGDHSVYWFKQSSG--HP-EGVLYTKGE---RNGRCKKTTESQ--TQSCVYSLHKNNISRSDSGIYYCAVATCGEILFGRGTQLNI Nitr8-I GTSTVHQEPISEVHI-GDNITFTCRVQREDKKKCEAGHHALWFRETAEDLESAPGIIYTAGDIKKHEERCEEDSD----SQSCIYTLTKRSLSLSDAGVYYCAVHGCDKIMFGNGTRLEF Nitr9-I KHTVVKQHDLIPSHS-GDSVSLTCTVLNQ---KCVGNHSMYWLIIESQ--DYPPRIISTHGT---PVDQCEWISDADFRALRCVYSFSRKDFRLSNSATYSCTVTACGEKLDRNGSKLDI Nitr12-I SGPNLGTEHEPEFNP-GDSVNLHCSVLTE---RCEENHTIYWFRHEFG--DAHPGLIYKDGN---TTDQCEKRSEKD--VQSCIYNLPKKNLNLTDAGVYYCAVATCGEILFGNGSRINI 
bioRxiv preprint doi: https://doi.org/10.1101/2021.06.11.448072; this version posted June 11, 2021. The copyright holder for this preprint (which was not certified by peer review) is the author/funder, who has granted bioRxiv a license to display the preprint in perpetuity. It is made available under aCC-BY 4.0 International license.

\section{Bowfin}

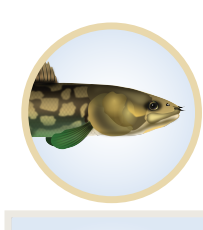

Identical residues

Structurally similar residues

Conserved

\section{Spotted Gar}

NITR1.1.4-V TDVISOPHLSVTAOLGNSVILPCFIVOT-RPMTLAW̄LKODFGOTPKYIV----TLPKFSEKPEFHRELNOSFSDRFKVRKT--ATSFTLTILNIOSADSALYYCRAFMYKOVAIGNGTLLLI NITR6.1.1-V GGAVSQPSLSLTVKPGDTVTLQCCVLMR-DPGHLAWFKQDTGQAPLCIL----STYSNVNGSTIHNGFSI---NRFKIQKG--SSSFNLSILHVELSDAGLYFCGMIPTTHMEFGNATLLQF

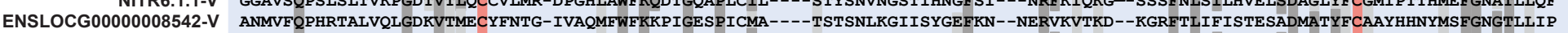

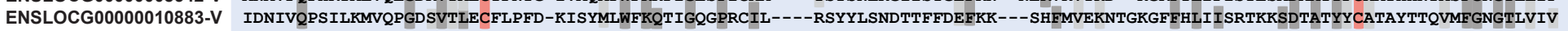

\section{Zebrafish}

Nitr1a-V GFDVVQEDNVKIVEAGGDVNFTCIFPGH-VPSTKAWFKQTTVGKYLQIV----SLDL-KKQLKWNSSFEK--TNRFNVTNV--YDYFNLTILKTKPSDSATYFCVVSAYETIGMGTATRLLV Nitr6a-V SNHSAEIVSLQTFKLGDDVIIKCFSTKISLGNTLVWYKQKTGQIPRAIT-----ISYIQLNKVIFEDEFKD---GRFSILPS--EDSFHLNITAATKQDTGIYYCGTVFLNLIEFISGAHLMI

Nitr9-V ISSTHPNAPPVFVKLGESVNMSCIYQSQ-MARHFSWYKHEPGQNPMLIS----TIYKYDHTAQFFNTFGN--DSRFSVLNE--NGVHLLTIRNVQFSDSATYYCGGAYSNVMEVVKGTRLIV Nitr10a-V FLKIMVSTANIQAQQGETVSMWCSHNIR-VTGNLYWFKQIDSAVPVTIMHMLFTESLQKVEPTYFNEFTK---NRLFMNQF--SKSTLLAI INVTTSDSGFYFCGFMDY-HIQFGNGTRLDV 
bioRxiv preprint doi: https://doi.org/10.1101/2021.06.11.448072; this version posted June 11, 2021. The copyright holder for this preprint (which was not certified by peer review) is the author/funder, who has granted bioRxiv a license to display the preprint in perpetuity. It is made available under aCC-BY 4.0 International license.

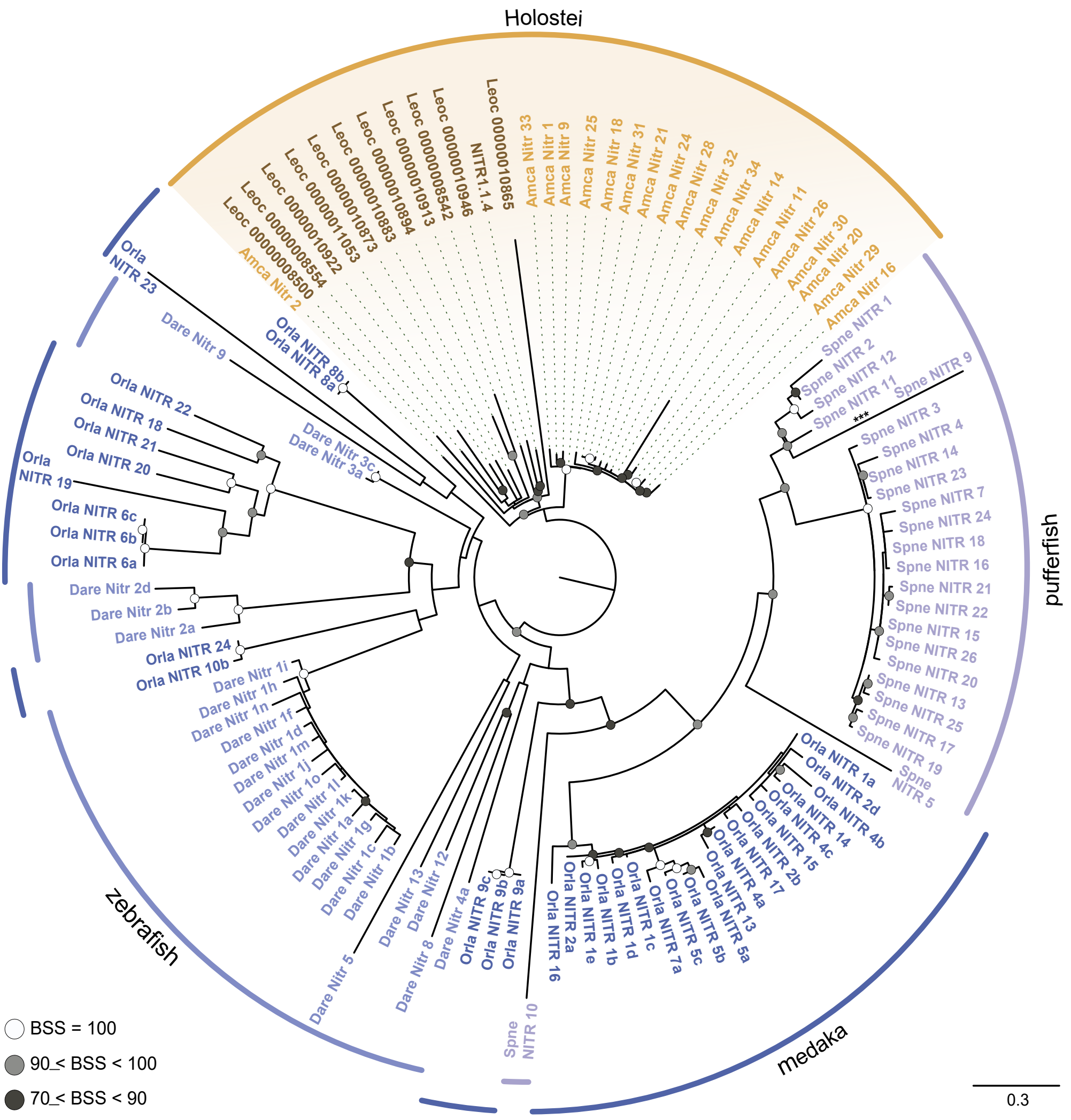


bioRxiv preprint doi: https://doi.org/10.1101/2021.06.11.448072; this version posted June 11, 2021. The copyright holder for this preprint (which was not certified by peer review) is the author/funder, who has granted bioRxiv a license to display the preprint in perpetuity. It is made available under aCC-BY 4.0 International license.

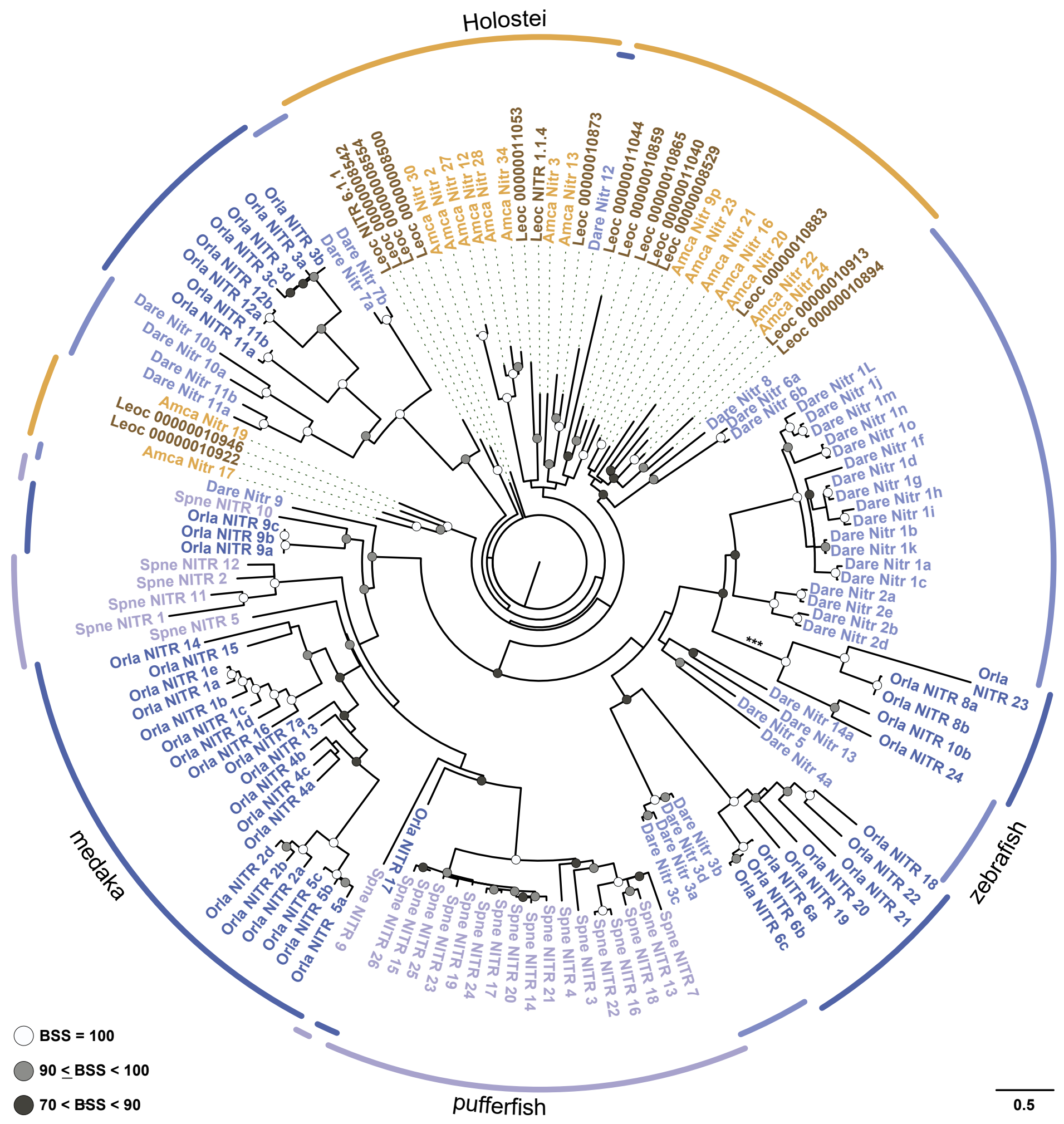


a

Genome Prediction

Ritr2

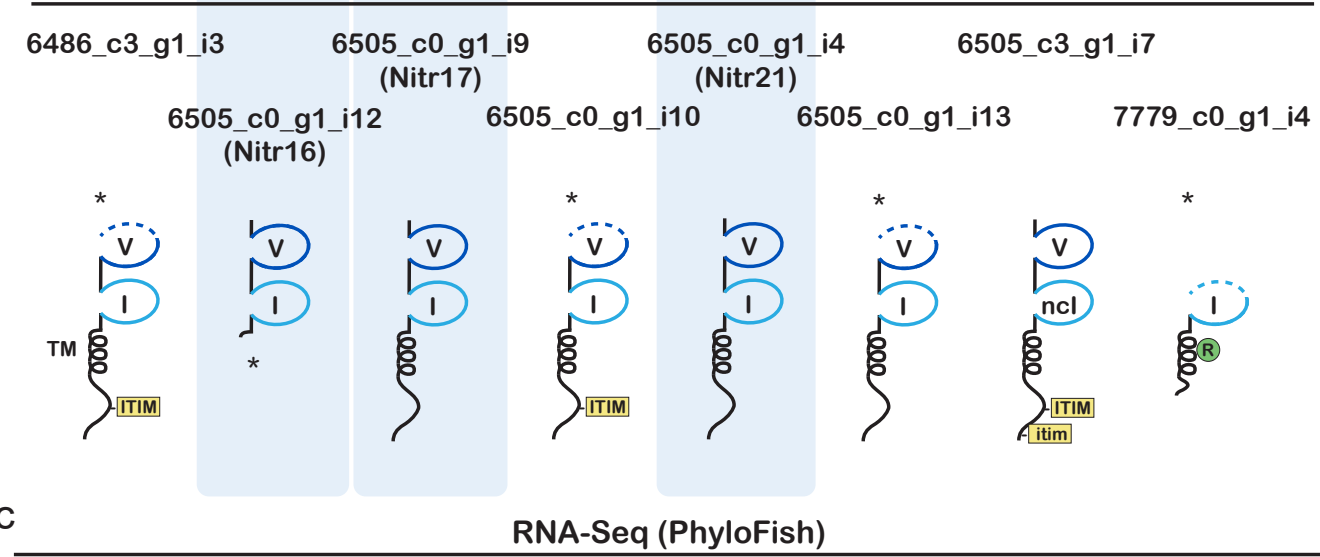

\begin{tabular}{lcccc}
\hline "NITR1.1.2" & “NITR3.1.2" & "NITR4.1.2” & LOC100695950.2.2 \\
& “NITR1.2.2" & $*$ & "NITR3.2.2" & "NITR4.2.2"
\end{tabular}

(v)

